\title{
Development and Application of ReaxFF Methodology for Understanding the Chemical Dynamics of Metal Carbonates in Aqueous Solutions
}

Nabankur Dasgupta ${ }^{1}$, Chen Chen ${ }^{2}$, Adri C.T. van Duin ${ }^{1,2,3, *}$

${ }^{1}$ Department of Engineering Science and Mechanics, The Pennsylvania State University, University Park, PA, 16802

${ }^{2}$ Department of Chemical Engineering, The Pennsylvania State University, University Park, PA, 16802

${ }^{3}$ Department of Mechanical Engineering, The Pennsylvania State University, University Park, PA, 16802

*Corresponding Author: acv13@psu.edu

\begin{abstract}
A new ReaxFF reactive force field has been developed for metal carbonate systems including $\mathrm{Na}^{+}$, $\mathrm{Ca}^{2+}$, and $\mathrm{Mg}^{2+}$ cations and the $\mathrm{CO}_{3}{ }^{2-}$ anion. This force field is fully transferable with previous ReaxFF water and water/electrolyte descriptions. The Me-O-C three-body valence angle parameters and $\mathrm{Me}-\mathrm{C}$ non-reactive parameters of the force field have been optimized against quantum mechanical calculations including equations of states, heats of formation, heats of reaction, angle distortions and vibrational frequencies. The new metal carbonate force field has been validated using molecular dynamics simulations to study solvation and reactivity of metal and carbonate ions in water at $300 \mathrm{~K}$ and $700 \mathrm{~K}$. The coordination radius and self-diffusion coefficient show good consistency with existing experiments and simulations results. The angular distribution analysis explains the structural preference of carbonate ions to form carbonates and bicarbonates, where $\mathrm{Na}^{+}$predominantly forms carbonates due to lesser angular strain, while $\mathrm{Ca}^{2+}$ and $\mathrm{Mg}^{2+}$ prefer to form bicarbonates monodentate in nature. Residence time distribution analyses on different systems reveal the role of ions in accelerating and decelerating dynamics of water and carbonate ions under different thermodynamic conditions. The formation and dissolution of
\end{abstract}


bicarbonates and carbonates in the solution were explored on the basis of protonation capability in different systems. The nucleation phenomenon of metal carbonates at ambient and supercritical conditions is explained from the perspective of clusters formation over time: $\mathrm{Ca}^{2+}$ ions can form prenucleation clusters at ambient temperature but shows a saturation with temperature, whereas $\mathrm{Na}^{+}$and $\mathrm{Mg}^{2+}$ ions show rapid increase in cluster size and amount upon increasing time and temperature.

\section{Introduction}

Alkaline and alkaline-earth metal carbonates serve in several important applications in geophysical $^{1}$, biological ${ }^{2}$ and industrial ${ }^{3}$ domain. Due to their high melting temperatures, they possess properties like high thermal and ionic properties making them suitable for fuel cells. ${ }^{4}$ Metal carbonates precipitation and mineral carbonation is currently one of the viable routes for carbon dioxide sequestration ${ }^{5}$. Solvation is an efficient way to precipitate metal carbonates and in determining the long-term stability of carbonates. Aqueous environments act as catalysts for metal ions to bind with carbonate anions leading to nucleation and precipitation in solution ${ }^{6}$. Thermodynamics play an important role in nucleation and crystal growth in solution and therefore understanding the solvation-reaction dynamics at ambient and high temperatures is crucial.

Several computational ${ }^{6-8}$ and experimental ${ }^{9-11}$ methods have been probed to monitor the ion association and clustering over the years. Experimental studies involving structural characterization with high resolution are limited owing to small size and intermittent lifetimes of such clusters. Modeling and simulation of such systems have paved the way in filling the void and provide support towards experimental quantifications. 
Predicting the prenucleation stage of ion clusters is a challenging task from a modeling perspective. Tommaso and de Leeuw studied the solvation and onset of nucleation ${ }^{12}$ for $\mathrm{CaCO}_{3}{ }^{13}$ and $\mathrm{MgCO}_{3}{ }^{14}$ complexes using Car-Parinello molecular dynamics (MD) simulations to understand their structure and dynamics. Chaka ${ }^{15}$ performed the molecular modeling and ab-initio thermodynamics simulations to determine the structure and thermodynamics of the known hydrated $\mathrm{CaCO}_{3}$ polymorphs and $\mathrm{Ca}$ analogues of hydrated $\mathrm{MgCO}_{3}$ to determine their potential role in forming prenucleation clusters, transient intermediates, or local coordination arrangements of amorphous $\mathrm{CaCO}_{3}$ in both aqueous and $\mathrm{CO}_{2}$ rich environments. $\mathrm{Ab}$-initio molecular dynamics (AIMD) simulations are computationally expensive limiting them to few nanometers system size and simulation times of tens to hundreds of picoseconds. Longer simulations of systems containing thousands to ten thousand of atoms is required to capture the ion aggregation, nucleation and growth phenomena. Classical molecular dynamics (MD) simulations are significantly less computationally expensive than AIMD and as such can generate nanosecond to microseconds of simulation of large systems. Bruneval and co-workers ${ }^{7,16}$ had built an empirical force field which had transferable potentials for different phases of calcium carbonates and its hydrated forms. The force field could capture the structural and dynamical properties of the systems and the early stages of calcium carbonate growth effectively. Raiteri et al ${ }^{6,17}$ parameterized the first force field which incorporates the calcite-aragonite phase transition and free energy of solvation of $\mathrm{Ca}^{2+}$ ions correcting deficiencies and accurately describing the thermodynamics of aqueous calcium carbonate system. Recently, polarizable force fields like AMOEBA were effective in addressing the ion pairing and multiple ion binding in calcium carbonate solutions ${ }^{18}$. Ottochian et al. ${ }^{19}$ calculated the diffusion and ionic conductivity of alkaline salt mixtures like sodium, lithium and potassium carbonate using the Born-Mayer Huggins and Coulomb potentials. Even though force 
fields with accurate potentials are capable of consistently describing the ions both in the solid and in aqueous solutions, examining the growth of carbonate salts is complicated due to the solution speciation of carbonates. The dominant species close to neutral $\mathrm{pH}$ is the bicarbonate anion. Although growth is normally conducted under basic $\mathrm{pH}$, the issue remains that bicarbonate may still prevail in solution, whereas carbonate is found in crystal. The question remains about the transfer of proton. The inclusion of reactivity to describe the speciation effect is an important approach to understand the protonation phenomenon. Reactive force fields have been able to address this shortcoming due to the combination of van der Waals, electrostatic interactions along with covalent terms which addresses reactivity within the system efficiently.

$\operatorname{ReaxFF}^{20,21}$ is an empirical force field that employs a bond-length/ bond-order/ bond-energy relationship to obtain a smooth transition between bonded and nonbonded systems, thus allowing reactions to happen during molecular dynamics simulation. During an MD run, the bond orders are updated every iteration, and the calculation of the system potential energy takes the bond-order into account. ReaxFF also considers nonbonded interactions for each pair of atoms, including van der Waals and Coulomb terms. ReaxFF also includes a geometry dependent polarizable charge calculation. These charges are updated in every iteration. ReaxFF methods have previously been developed for number of aqueous systems including metal ions and solid-liquid interfaces. ${ }^{22-26}$ Gale et al. ${ }^{27}$ had previously developed a ReaxFF force field to study the aqueous and solid $\mathrm{CaCO}_{3}$ systems which adjusted the functional forms of the present ReaxFF empirical potentials by applying tapering functions to all to ensure smooth truncation. It also considered $\mathrm{Ca}^{2+}$ as a fixed di-cation regardless of whether it is in aqueous solution or bulk phase of crystalline calcium carbonate. Anything lesser than +2 charge led to under binding of water to $\mathrm{Ca}^{2+}$ ions. Our present description of the force field removes this assumption as charge is dynamic in nature and can be 
partial, making our current force field more consistent and more transferable with other ReaxFF descriptions. The charge calculated in the present ReaxFF framework is using the Electronegativity Equalization Method $^{28}(\mathrm{EEM})$ and updated in every iteration. We provide a ReaxFF methodology which considers three different metal ions: $\mathrm{Na}^{+}, \mathrm{Ca}^{2+}$ and $\mathrm{Mg}^{2+}$ along with the $\mathrm{CO}_{3}{ }^{2-}$ description to understand the structural and dynamical properties of each system.

In this paper, we aim to study the solvation and reactivity of three different metal ions $\left(\mathrm{Na}^{+}, \mathrm{Ca}^{2+}\right.$ and $\left.\mathrm{Mg}^{2+}\right)$ and carbonate ion $\left(\mathrm{CO}_{3}{ }^{2-}\right)$ in water. These three metal ions are very unique in nature and studying their dynamics in water at different thermodynamic conditions will provide evidence of their unique behavior. We detail the ReaxFF force field parameterization of the metal carbonate framework and validation with DFT studies. We study the dynamics of three different metal carbonate ion pairs in water at $300 \mathrm{~K}$ and $700 \mathrm{~K}$. We assess the structural arrangement of species in terms of radial distribution function (RDF) and Angular distribution function (ADF). The dynamics of the solvation shell was established by residence time distribution, self-diffusion coefficient and shear viscosity calculations. Finally, we detail the thermodynamic effect on the metal ions leading nucleation in the solution.

\section{Force field development section}

The ReaxFF development branch is distributed into three main branches: combustion, aqueous and independent branch. ${ }^{21}$ The parameters in branch are inter-transferable as they share the same first row of atomic parameters and have identical general parameters. We used the general $\mathrm{C} / \mathrm{O} / \mathrm{H}$ parameters which were derived from the ReaxFF protein force field ${ }^{29}$ where the atomic C parameters were derived from the combustion force field ${ }^{30}$ and $\mathrm{H} / \mathrm{O}$ atomic parameters came from the first generation water force field. ${ }^{31}$ The Ca-O parameters were taken from the Pitman force field ${ }^{32}, \mathrm{Mg}-\mathrm{O}$ parameters from Protein force field ${ }^{29}$ and $\mathrm{Na}-\mathrm{O}$ parameters from the recently 
developed Fedkin et al. ${ }^{33}$ force field. The general description of total interaction energy in ReaxFF is as follows:

$E_{s y s}=E_{b o n d}+E_{v a l}+E_{\text {tor }}+E_{\text {over }}+E_{\text {under }}+E_{l p}+E_{v d W a a l s}+E_{\text {coulomb }}$

In Eq 1, $E_{b o n d}$ (bond energy), $E_{\text {val }}$ (valence angle energy), $E_{t o r}$ (torsion angle energy), $E_{\text {over }}$ (overcoordination penalty energy), $E_{\text {under }}$ (under-coordination penalty energy), and $E_{l p}$ (lone-pair energy) are bond-order-dependent terms, meaning that the contribution of these energies disappears upon bond dissociation, leaving with only the nonbonded interactions. Nonbonded interaction terms include $E_{\text {coulomb }}$ (Coulomb energy) and $E_{v d W a a l s}$ (van der Waals energy), and they are calculated between all atom pairs in the system. For both types of interactions, ReaxFF employs shielded potentials to avoid excessive repulsions and unphysical charges between atoms that are at close distances. We use $\mathrm{EEM}^{28}$ for calculations of the atomic charges in ReaxFF, and this geometry-dependent charge calculation method makes ReaxFF a reactive force field that can handle the polarization of a system.

In this study, we optimized ReaxFF parameters for $\mathrm{Ca}_{-} \mathrm{CO}_{3}{ }^{2-}, \mathrm{Mg}_{-}-\mathrm{CO}_{3}{ }^{2-}, \mathrm{Na}-\mathrm{CO}_{3}{ }^{2-}$ interactions to obtain a transferable potential for metal carbonate interactions. In general, we trained the Me-O-C angle and Me-C off-diagonal parameters to develop this force field. The parameter sets were developed by training against $\mathrm{QM}$ and available literature data.

Note that preliminary versions of the force field presented here have been used in two previously published studies. One of the studies was to gain insight in the speciation mechanism of waterformic acid mixtures at sodium montmorillonite surfaces. ${ }^{34}$ Another study was to understand the physicochemical mechanism at the rock-calcite interface due to friction ${ }^{35}$.

The training set to develop our present force field have the following informations: 
1. Equations of states of different condensed phase polymorphs of calcium carbonates specifically Calcite, Aragonite and Vaterite as shown in Figure 1; Magnesium Carbonate and Sodium Carbonate crystals. ReaxFF force field was trained against the difference in energies between the phases at a particular volume and the most stable volume.

2. Heats of formation and Heats of reaction of the different metal carbonates, metal oxides and metal hydroxides. ReaxFF was trained against the literature values obtained from the National Institute of Science and Technology database. ${ }^{36}$

3. Angular distortions of Me-O-C and Me-C. The ReaxFF parameters were trained against the energy differences between the constrained molecule and the minimum state.
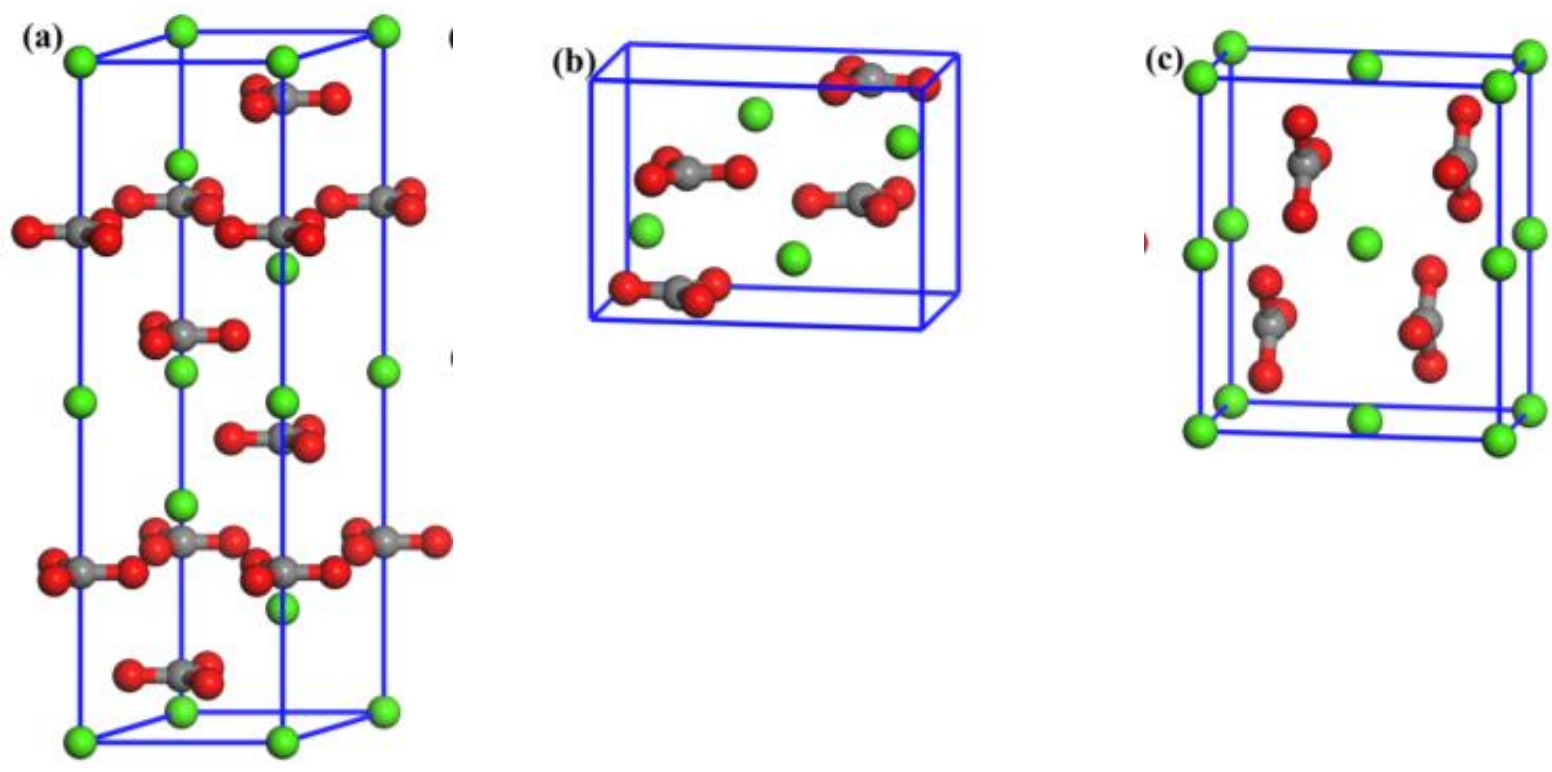

Figure 1: Unit cell of $\mathrm{CaCO}_{3}$ polymorphs (a) Calcite (b) Aragonite and (c) Vaterite.

4. Vibrational frequencies for molecular $\mathrm{NaHCO}_{3}, \mathrm{MgCO}_{3}$ and $\mathrm{CaCO}_{3}$. The molecular vibrational frequencies obtained from ReaxFF are trained against the DFT normal modes of vibrations. 
We used the general ReaxFF parameter optimization strategy which was first introduced in the non-reactive polarizable force field developed by van Duin et $\mathrm{al}^{20}$ given by Eq 2 . We used the single parameter linear search optimization technique. Parameter correlations which are quite extensive in ReaxFF are captured by performing multiple loops over the optimizable force field parameters until the force field error converges. The weights depend on (a) the relevance of a particular training set data points which are closer to the equilibrium are given higher weights and (b) the expected error in the DFT data; for example, metal oxide reactions we anticipate significant uncertainty in the DFT data as such, these points are given lower weights in the training set.

total error $=\sum_{i=1}^{n}\left(\frac{X_{i, Q M}-X_{i, R e a x F F}}{\sigma_{i}}\right)^{2}$

\section{Quantum Mechanical Methods}

The Density Functional Theory (DFT) calculations of Calcium Carbonate molecules were performed with the Jaguar ${ }^{37}$ software using M06-2x functional with LACV3P++** basis set. The DFT calculations for Magnesium Carbonate and Sodium Bicarbonate molecules were performed using B3LYP 6-31G(d,p)++ basis set in Jaguar. Full geometry optimizations were performed on these molecules without any symmetry or structural constraints. To obtain the potential energy profile along the Me-O-C angle and Me-C off-diagonal, the constrained geometry optimization was applied in the $\mathrm{Me}-\mathrm{O}-\mathrm{C}$ angle ranging from $65^{\circ}$ to $130^{\circ}$ and $\mathrm{Me}-\mathrm{C}$ off-diagonal ranging from

$1.0 \AA$ to $4.2 \AA$. The vibrational frequencies were also obtained using the same set of DFT calculations for each carbonate molecule. The ReaxFF frequencies of each molecule were trained against the DFT normal mode of vibrations.

Periodic DFT calculations for metal carbonate and metal oxide phases were carried out using the Vienna ab initio simulation package ${ }^{38}$ (VASP) in conjunction with projected augmented wave ${ }^{39}$ 
(PAW) pseudopotentials and the Perdew-Burke-Ernzerhof ${ }^{40}$ (PBE) parametrization of the generalized gradient approximation (GGA) exchange-correlation functional. The plane wave kinetic energy cutoff value was set to be $520 \mathrm{eV}$, while the Monkhorst-Pack method or Gammacentered mesh was used for k-points generation with following the protocols associated with the crystal structures on Materials Project database. Spin polarization and zero damping DFT-D3 method of Grimme corrections were used in all calculations.

\section{Simulation Details}

ReaxFF MD simulations were performed for three different metal ( $\mathrm{Na}, \mathrm{Ca}, \mathrm{Mg}$ ) carbonate aqueous solutions at $3 \mathrm{~m}$ concentrations for ambient $(300 \mathrm{~K})$ and supercritical $(700 \mathrm{~K})$ temperature to understand the structure, dynamics and speciation of the different ions in solution. A simulation box containing 1000 water molecules and equivalent amounts of metal ions and carbonate ions was created for a charge neutral aqueous solution. The initial system was created at a very low density, and then minimized and compressed to the desired box size. The temperature of the system was gradually increased to $300 \mathrm{~K}$. The system was equilibrated at $300 \mathrm{~K}$ for $200 \mathrm{ps}$. The final configuration at $300 \mathrm{~K}$ was taken and the system was gradually ramped up to a temperature of 700 K. Periodic boundary condition was maintained to avoid boundary effects caused by finite size and considering the system as an infinite one. We equilibrated the system at both temperatures ( $300 \mathrm{~K}$ and $700 \mathrm{~K}$ ) for $100 \mathrm{ps}$ and conducted NVT MD simulations for $1 \mathrm{~ns}$. The last $0.5 \mathrm{~ns}$ were considered for the statistical analysis of the dynamical properties.

In our simulation, the time step was set to 0.25 fs to integrate Newton's equation of motion by velocity-verlet algorithm. A Berendsen thermostat with a 100 fs damping constant was used to control the temperature of the entire system. All of the ReaxFF MD simulations were performed used the Amsterdam Density Functional ${ }^{41}$ software package. 
We performed a series of NVT MD simulations for the calculation of the shear viscosity in electrolyte solutions for $\mathrm{Na} 2 \mathrm{CO} 3, \mathrm{CaCO} 3$ and $\mathrm{MgCO} 3$ at $300 \mathrm{~K}$ and $700 \mathrm{~K}$. The systems were equilibrated for 250 ps under NVT ensemble using Nose-Hoover thermostat with a relaxation constant of 100 fs. To collect trajectories for viscosity calculation, we performed NVT MD simulations for $1 \mathrm{~ns}$ using a time step of 0.25 fs. For parallel ReaxFF MD simulations, we used the LAMMPS/ReaxFF implementation to calculate the shear viscosities of each electrolyte-water system.

\section{Results and Discussions}

\subsection{Comparisons with DFT}

The force field interaction parameters for Me-O-C angle and Me-C off-diagonal were trained against the DFT calculations of Equations of States of the crystal polymorphs of Sodium, Calcium and Magnesium Carbonates. For $\mathrm{CaCO}_{3}$ we considered the most common crystal polymorphs: Calcite, Aragonite and Vaterite. While Calcite is the most stable polymorph at ambient temperature, Aragonite exist at higher thermodynamic condition and Vaterite is a metastable phase. Vaterite is highly soluble in water and can disintegrate to Calcite at room temperature and Aragonite at high temperature. We considered two different crystal polymorphs of Magnesite $\left(\mathrm{MgCO}_{3}\right)$ for the EOS calculations: trigonal which exist at normal thermodynamic conditions and orthorhombic which is thermodynamically unstable at normal conditions. For $\mathrm{Na}_{2} \mathrm{CO}_{3}$ crystals also known as "Soda Ash", we considered the alpha (trigonal), beta (hexagonal) and gamma (monoclinic) polymorphs. The volume-energy relationship (equations of state) of eight crystal structures, were included as references to define the ReaxFF parameters. Since these crystals have different coordination numbers, the equations of state data can lead to the parameterization of the three-body energies and their relationship to the bond order. The environment around each metal 
ions can be quite different and hence the parameterization of the force field provides reasonable energy description during the compression and expansion of their respective crystals. We deformed the crystals uniformly in all directions by $\pm 10 \%$ in order to fit the Energy as a function of Volume as shown in Figure 2. Points near the equilibrium were given higher weights to capture the curvature properly. We obtain a decent fit with DFT data as seen in Figure 2. Note that for applications requiring accurate mechanical properties it may be advisable to improve the ReaxFF reproduction of these data - but this will go at the expense of the heats of formation and reaction discussed later in this manuscript.
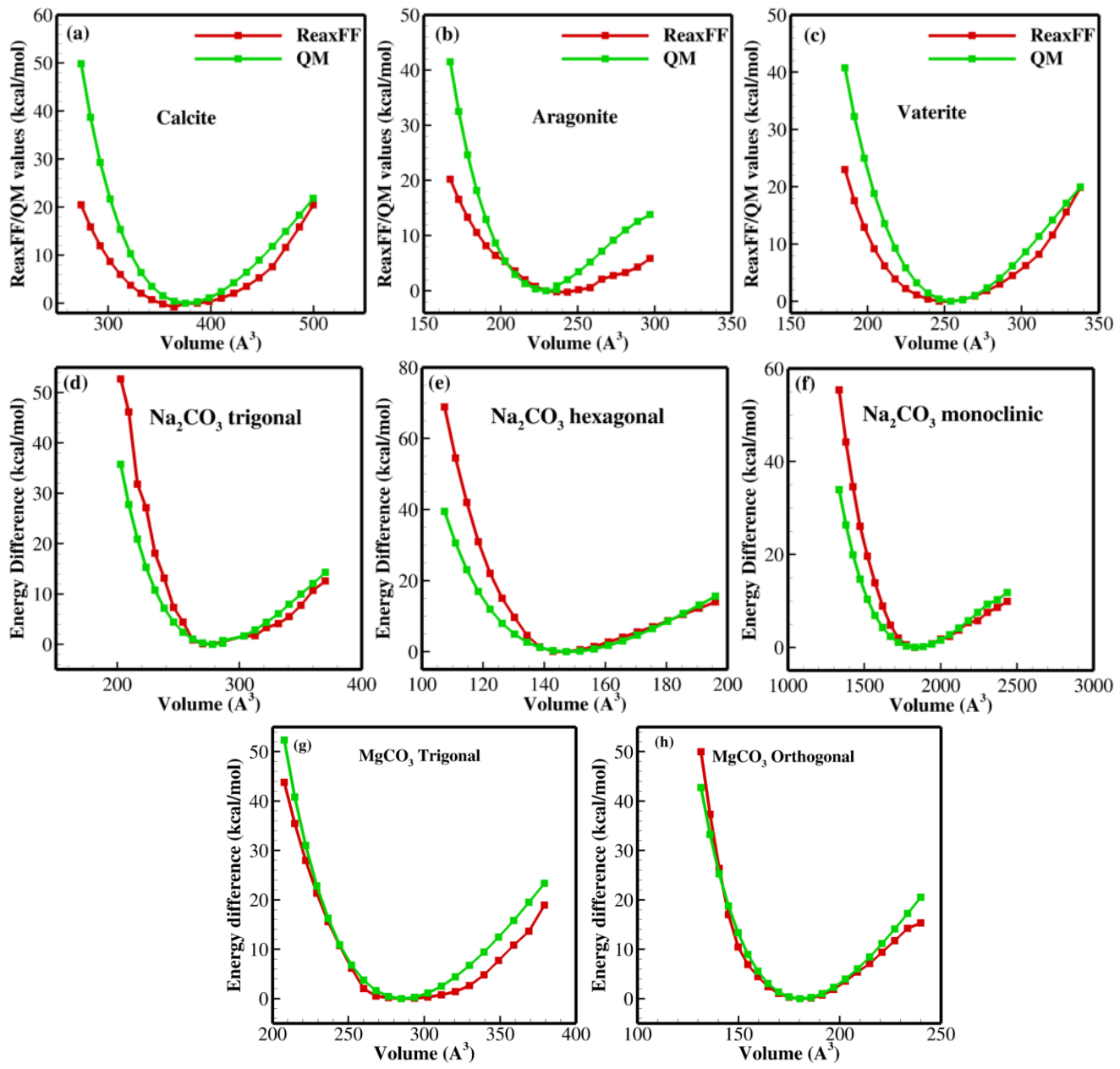

Figure 2: Equation of state comparisons for (a) Calcite, (b) Aragonite, (c) Vaterite, (d) Trigonal $\mathrm{Na}_{2} \mathrm{CO}_{3}$ (e) Hexagonal $\mathrm{Na}_{2} \mathrm{CO}_{3}$ (f) Monoclinic $\mathrm{Na}_{2} \mathrm{CO}_{3}$ (g) Trigonal $\mathrm{MgCO}_{3}$ and (h) Orthogonal $\mathrm{MgCO}_{3}$. 
For the case of the aqueous metal carbonate system, it has been recently shown that it is essential to ensure that the thermodynamics of the model is taken into account during the parameterization, something that has been widely overlooked in previous studies ${ }^{42-44}$ On the basis of such model, it is then possible to obtain results for solution speciation that are in good quantitative agreement with the experimental and ab-initio data. The phase change thermodynamic data for the conversion from calcite to aragonite is found to be $0.34 \mathrm{kcal} / \mathrm{mol}$ for which ReaxFF predicts an energy difference of $1.78 \mathrm{kcal} / \mathrm{mol}$. The heat of formation and heat of reactions of the crystal phases are important thermodynamic information against which parameterization of the force field can accurately capture and describe the reactivity of the system. The covalent bond parameters can be significantly refined against these features making the force field suitable to study systems at range of thermodynamic conditions. Both the heat of reaction and formation show reasonable agreement with the literature data and such the average error in the thermodynamic data is within $13 \%$ as seen in Table 1, 2 and 3 for $\mathrm{CaCO}_{3}, \mathrm{MgCO}_{3}$ and $\mathrm{Na}_{2} \mathrm{CO}_{3}$ respectively. It should be noted that there is a statistical uncertainty in the values which arises from the hydration energy of the cations and carbonates present in the solution.

Table 1: Comparisons of heat of formation and reaction of Calcium Carbonate

\begin{tabular}{cccc}
\hline & Reactions & $\begin{array}{c}\text { QM } \\
(\mathrm{kcal} / \mathrm{mol})\end{array}$ & $\begin{array}{c}\text { ReaxFF } \\
(\mathrm{kcal} / \mathrm{mol})\end{array}$ \\
\hline \multirow{4}{*}{$\begin{array}{c}\text { Heat of } \\
\text { formation }\end{array}$} & $\mathrm{Ca}+1 / 2 \mathrm{O}_{2}---->\mathrm{CaO}$ & -151.88 & -177.92 \\
& $\mathrm{Ca}+\mathrm{O}_{2}+\mathrm{H}_{2}---->\mathrm{Ca}(\mathrm{OH})_{2}($ gas $)$ & -146 & -183.63 \\
& $\mathrm{Ca}+\mathrm{O}_{2}+\mathrm{H}_{2}---->\mathrm{Ca}(\mathrm{OH})_{2}($ solid $)$ & -235.7 & 303.43 \\
\cline { 2 - 3 } $\begin{array}{c}\text { Heat of } \\
\text { reaction }\end{array}$ & $\mathrm{Ca}+\mathrm{C}+3 / 2 \mathrm{O}_{2}---->\mathrm{CaCO}_{3}$ (solid) & -288.6 & -237.05 \\
\cline { 3 - 4 } & $\mathrm{CaO}+\mathrm{CO}_{2}---->\mathrm{CaCO}_{3}$ & -42 & -50.46 \\
\hline
\end{tabular}


Table 2: Comparisons of heat of formation and reaction of Magnesium Carbonate

\begin{tabular}{|c|c|c|c|}
\hline & Reactions & $\mathrm{QM}(\mathrm{kcal} / \mathrm{mol})$ & ReaxFF (kcal/mol) \\
\hline \multirow{2}{*}{$\begin{array}{l}\text { Heat of } \\
\text { formation }\end{array}$} & $\mathrm{Mg}+1 / 2 \mathrm{O}_{2}----->\mathrm{MgO}$ & -143.7 & 140.89 \\
\hline & $\mathrm{Mg}+\mathrm{C}+3 / 2 \mathrm{O}_{2}----->\mathrm{MgCO}_{3}($ solid $)$ & 265.7 & 266.52 \\
\hline \multirow{2}{*}{ Heat of reaction } & $\mathrm{Mg}+\mathrm{O}_{2}----->\mathrm{MgO}_{2}$ & -150 & -145.57 \\
\hline & $\mathrm{MgO}+\mathrm{CO}_{2}----->\mathrm{MgCO}_{3}$ & -28 & -22.26 \\
\hline
\end{tabular}

Table 3: Comparisons of heat of formation and reaction of Sodium Carbonate

\begin{tabular}{cccc}
\hline & Reactions & $\begin{array}{c}\text { QM } \\
(\mathrm{kcal} / \mathrm{mol})\end{array}$ & $\begin{array}{c}\text { ReaxFF } \\
(\mathrm{kcal} / \mathrm{mol})\end{array}$ \\
\hline \multirow{3}{*}{ Heat of formation } & $\mathrm{Na}+1 / 2 \mathrm{O}_{2}+1 / 2 \mathrm{H}_{2}----->\mathrm{NaOH}$ & -101.9 & 105.28 \\
& $\mathrm{Na}+\mathrm{C}+3 / 2 \mathrm{O}_{2}+1 / 2 \mathrm{H}_{2}----->\mathrm{NaHCO}_{3}$ & -227.46 & -235.88 \\
\cline { 1 - 2 } Heat of reaction & $\mathrm{Na}_{2} \mathrm{O}+\mathrm{CO}_{2}----->\mathrm{Na}_{2} \mathrm{CO}_{3}$ & -76.8 & -86.24 \\
\hline
\end{tabular}

The Angular distortion calculations were performed as mentioned in Section 2. Training against the angle scanning data of the metal carbonates allow the force field to capture the atomic orientation properly while reacting or ionizing in a system. The ReaxFF parameterization was done based on the Angle scanning of the three metal carbonates as seen in Figure 3. The energy curve shapes generated by the ReaxFF method are in good agreement with the QM data. 

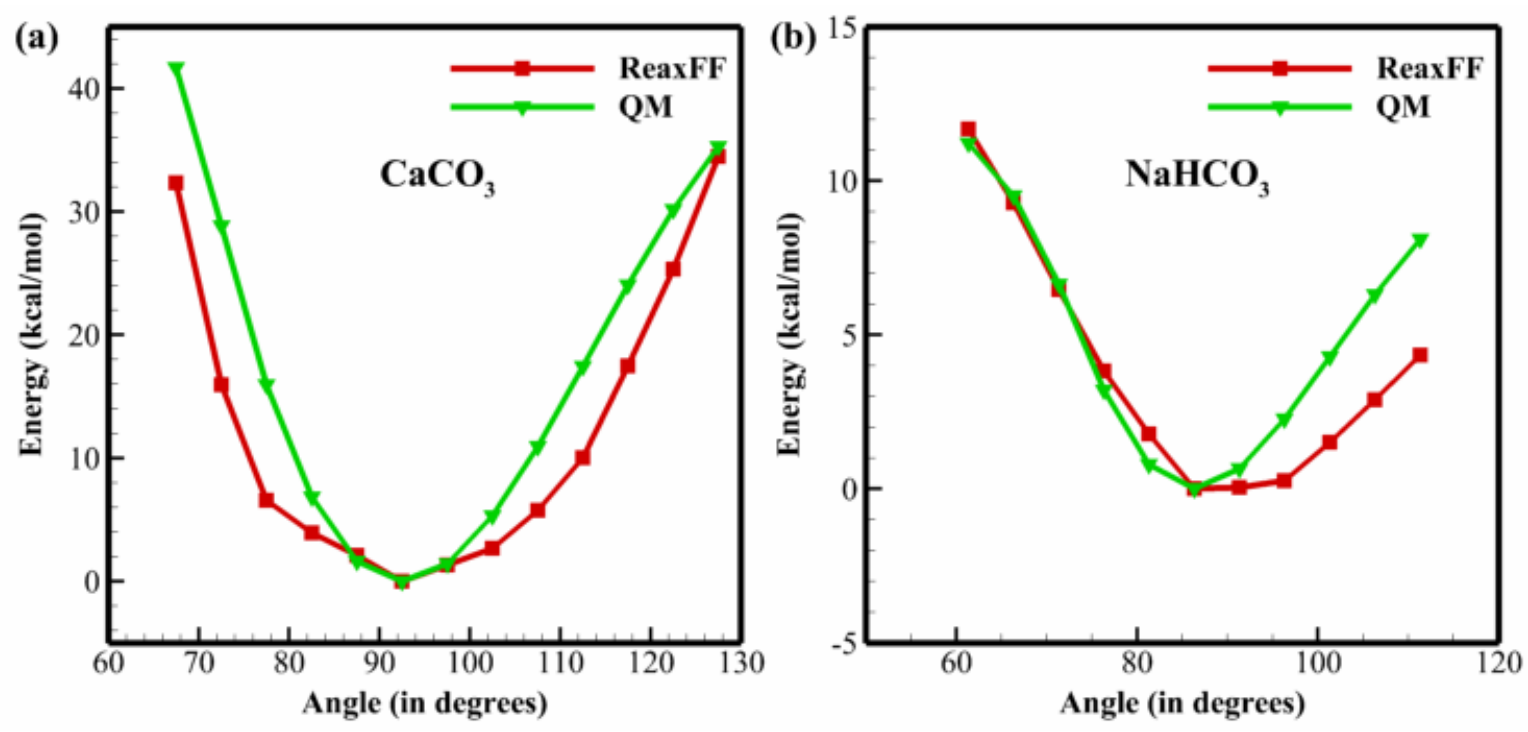

Figure 3: Angle scanning of Me-O-C angle for (a) $\mathrm{CaCO}_{3}$ and (b) $\mathrm{NaHCO}_{3}$ molecules.

The vibrational frequencies of the metal carbonate molecules were calculated as explained in Section 2. The ReaxFF frequencies were obtained from calculating the Hessian of the Energy matrix to obtain the normal modes of vibrations. We computed the vibrational frequencies for $\mathrm{CaCO}_{3}$ and $\mathrm{NaHCO}_{3}$, where the frequencies of the different modes of stretch were trained against the DFT modes. The comparisons of the vibrational frequencies for ReaxFF and DFT are shown in Figure 4. The range of $\mathrm{CaCO}_{3}$ and $\mathrm{NaHCO}_{3}$ modes were different due to the presence of the $\mathrm{H}$ atom in $\mathrm{NaHCO}_{3}$ which vibrates at a much larger frequency. The quantitative agreement for the vibrational frequencies were reasonable. 


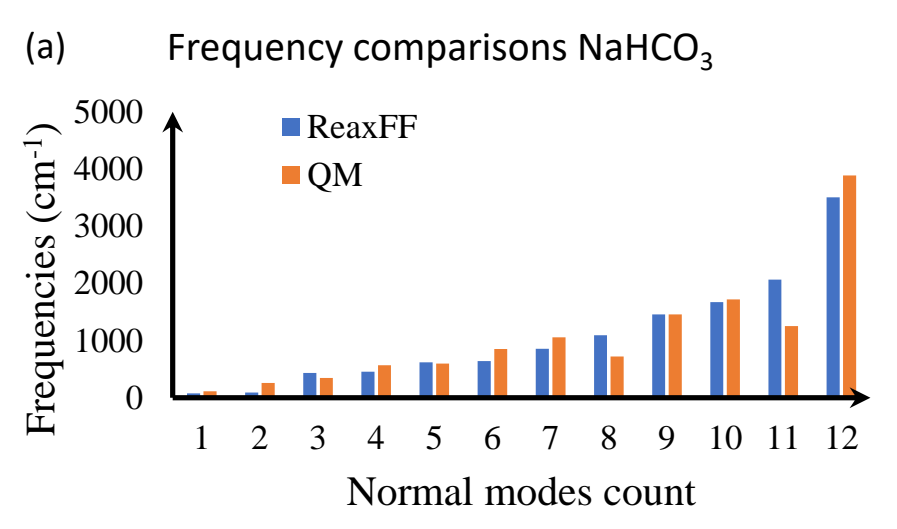

(c) Frequency comparisons $\mathrm{CaCO}_{3}$

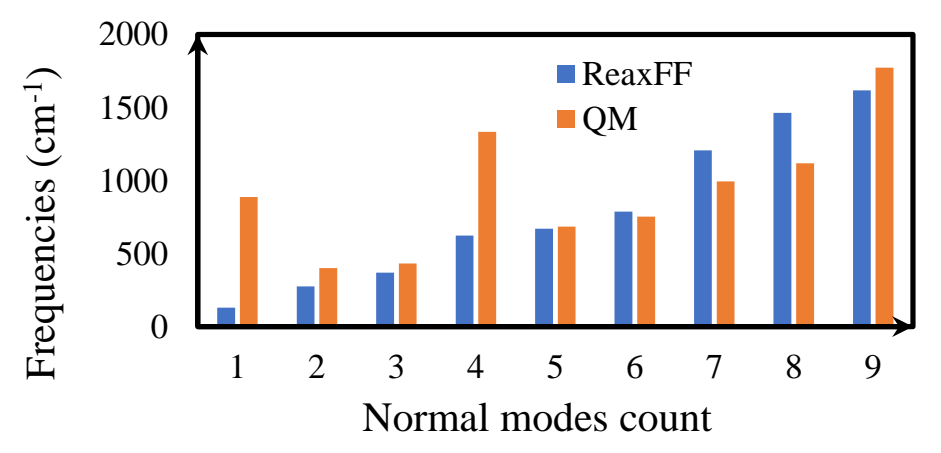

(b)

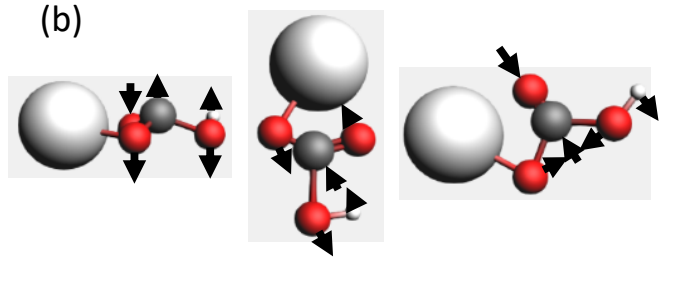

(d)

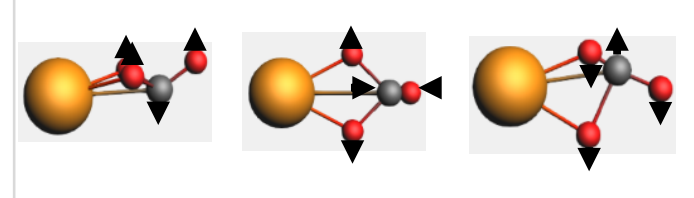

Figure 4: Vibrational frequency normal modes comparison between ReaxFF and QM for (a) $\mathrm{NaHCO}_{3}$ and (c) $\mathrm{CaCO}_{3}$. Stretch modes shown for (a) $\mathrm{NaHCO}_{3}$ and (b) $\mathrm{CaCO}_{3}$

\subsection{Diffusion Coefficient}

Self-diffusion coefficients give us an estimate about the transport properties of ions in solutions which helps us to understand dynamical changes to various chemical systems. We have calculated the diffusion coefficient of metal ions, carbonate ions and water for each system at $300 \mathrm{~K}$ and 700 $\mathrm{K}$. The diffusion coefficient is calculated from the long-time limit of the mean square displacement (MSD) given by Eq 3

$$
D_{M D}=\lim _{t \rightarrow \infty} \frac{1}{6 N_{i} t}\left\langle\sum_{j=1}^{N_{i}}\left(r_{j, i}(t)-r_{j, i}(0)\right)^{2}\right\rangle
$$


Where $r_{j, i}(t)$ is the position of the $j$ th molecule of species $i$ at time $t$, and $N_{i}$ is the number of molecules of species $i$ in the system.

We have obtained $D_{M D}$ from Eq 3 for metal ions, carbonate ions and water molecules by making the least squares fit of MSD plots from the trajectories of simulations of $200 \mathrm{ps} . D_{M D}$ is calculated from the slope of the MSD plot which is fitted to the linear part (diffusive regime) of the graph. The MSD plots are reported in Figure 5 and the diffusive regime is considered from 0 to 200 ps as it gives a well-defined linear profile in this time-range.
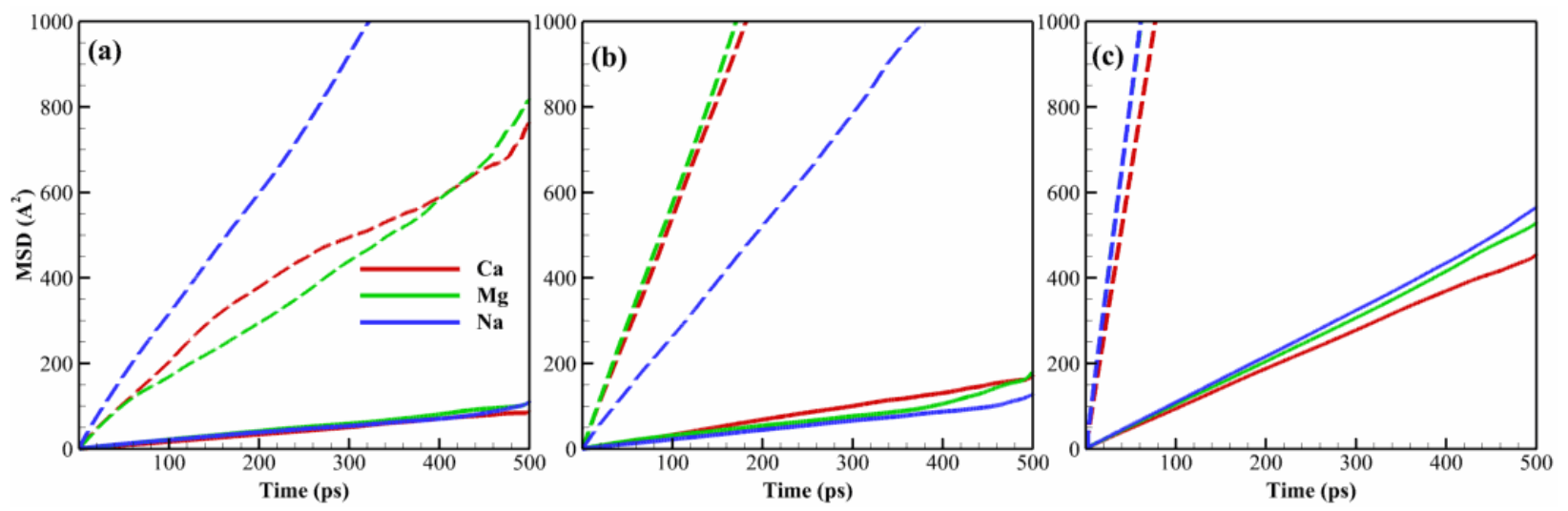

Figure 5: Mean square displacement plots at $300 \mathrm{~K}$ (solid lines) and $700 \mathrm{~K}$ (dashed lines) for (a) Metal ions, (b) Carbonate ions and (c) water molecules

It is important to consider the system size effects as the long-range interactions can lead to systematic errors in the calculation of self-diffusion if no corrections are applied. The system randomness increases at high temperature which affects the shear viscosity of the aqueous solution changing the diffusivity of the ions significantly. This approach was first developed by Yeh and Hummer $^{45}$ and used in literature to predict diffusion coefficient at the thermodynamic limit. The following corrections were applied in Eq. 4 for incorporating the system size effects:

$D_{\infty}=D_{M D}+\frac{k_{B} T \xi}{6 \pi \eta L}$ 
Where $D_{\infty}$ is the self-diffusion coefficient corrected by the system size effects, $D_{M D}$ is the selfdiffusion coefficient obtained from the MSD calculation, $k_{B}$ is the Boltzmann constant, $T$ is the absolute temperature, $\xi \approx 2.837298$ is a dimensionless constant of a periodic lattice, $\eta$ is the shear viscosity and $L$ is the length of the cubic simulation box.

The microscopic friction in an aqueous salt solution is largely dependent on the shear viscosity of the solution. We calculate the shear viscosity of the solution using the Green-Kubo autocorrelation of the off-diagonal components of the stress tensor given by Eq. 5 .

$\eta=\lim _{t \rightarrow \infty} \frac{1}{2 t} \frac{V}{k_{B} T}\left\langle\left(\int_{0}^{t} P_{\alpha \beta}\left(t^{\prime}\right) d t^{\prime}\right)^{2}\right\rangle$

Where $V$ is the volume of the system, $k_{B}$ is the Boltzmann constant, $P_{\alpha \beta}$ the three off-diagonal components of stress-tensor, $T$ is the absolute temperature and $t$ is the simulation time. The viscosity of the solution increases with the increase in density of the system and is inversely proportional to the diffusivity of ions through the solution. The shear viscosity of different electrolyte systems is reported in Table 4. The calculated self-diffusion coefficients with finite size effects $\left(D_{\infty}\right)$ have been shown in Table 5 .

Table 4: Shear viscosity (in Pa.s) of different aqueous metal carbonate solutions at $300 \mathrm{~K}$ and 700 $\mathrm{K}$.

\begin{tabular}{cccc}
\hline & $\mathrm{CaCO}_{3}$ & $\mathrm{MgCO}_{3}$ & $\mathrm{Na}_{2} \mathrm{CO}_{3}$ \\
\hline $300 \mathrm{~K}$ & $1.503 \times 10^{-3}$ & $1.249 \times 10^{-3}$ & $1.026 \times 10^{-3}$ \\
$700 \mathrm{~K}$ & $1.501 \times 10^{-4}$ & $1.342 \times 10^{-4}$ & $1.325 \times 10^{-4}$ \\
\hline
\end{tabular}


Table 5: Self-diffusion coefficients of metal ions, carbonate ions and water molecules at $300 \mathrm{~K}$ and $700 \mathrm{~K}$.

\begin{tabular}{cccccccccc}
\hline $\mathrm{Ca}^{2+}$ & $\mathrm{Mg}^{2+}$ & $\mathrm{Na}^{+}$ & $\begin{array}{c}\mathrm{CO}_{3}{ }^{2-} \\
(\mathrm{Ca})\end{array}$ & $\begin{array}{c}\mathrm{CO}_{3}{ }^{2-} \\
(\mathrm{Mg})\end{array}$ & $\begin{array}{c}\mathrm{CO}_{3}{ }^{2-} \\
(\mathrm{Na})\end{array}$ & $\begin{array}{c}\mathrm{H}_{2} \mathrm{O} \\
(\mathrm{Ca})\end{array}$ & $\begin{array}{c}\mathrm{H}_{2} \mathrm{O} \\
(\mathrm{Mg})\end{array}$ & $\begin{array}{c}\mathrm{H}_{2} \mathrm{O} \\
(\mathrm{Na})\end{array}$ \\
\hline $300 \mathrm{~K}$ & 0.0285 & 0.0345 & 0.032 & 0.0566 & 0.0451 & 0.0373 & 0.1561 & 0.1711 & 0.1807 \\
$700 \mathrm{~K}$ & 0.3064 & 0.2496 & 0.5058 & 0.937 & 1.0399 & 0.4354 & 2.1487 & 2.6758 & 2.784 \\
\hline
\end{tabular}

Diffusion of water molecules in aqueous carbonate solutions increases with increase in temperature due to the coexisting vapor phase at supercritical temperature. Cations show different diffusion dynamics in supercritical water compared to ambient water. At ambient conditions, $\mathrm{Na}^{+}$ and $\mathrm{Ca}^{2+}$ show higher binding with water as they can establish strong hydrogen bonding network around their coordination shell. $\mathrm{Na}^{+}$ions usually show 6-fold coordination at ambient condition leading to significant affinity with water in its coordination shell. In the case of $\mathrm{Ca}^{2+}$, the most likely coordination is 7-fold; however, the 8-fold coordination is also possible but it is less stable. and hence it is most stable. In the case of $\mathrm{Mg}^{2+}$, only a 6-fold coordination with oxygen is thermodynamically accessible, and to form a contact ion pair (CIP) a molecule from the $\mathrm{Mg}^{2+}$ hydration shell has to be displaced, which is an activated process with a free energy barrier. With $\mathrm{Mg}^{2+}$ only 6-fold coordination with respect to oxygen, where five oxygens belong to water and one oxygen belong to carbonate ion is possible. The 6-fold coordination state lowers the contribution of the average hydration state. All other configurations are high on energy barrier to visit making it a very stable state. For $\mathrm{Ca}^{2+}$, the cation can accommodate an extra oxygen in the hydration shell for a relatively small energetic cost, and hence CIP can be formed without crossing a high energy barrier. Therefore, solvation of $\mathrm{Ca}^{2+}$ is easier compared to $\mathrm{Mg}^{2+}$ making it less diffusive in water. Both bicarbonate and carbonate has been studied previously using first principles are monodendate in nature and preferentially form ion-pairing with $\mathrm{Ca}^{2+}$ and $\mathrm{Mg}^{2+}$. At supercritical condition, ions lose their binding affinity for water due to low dielectric strength. 
Binding with carbonate ion is still effective at high temperature and ions can nucleate and precipitate as clusters. Diffusion of metal ions, carbonate ion and water molecules significantly increase at high temperature by an order. $\mathrm{Ca}^{2+}$ is unable to find a 7-fold coordination making it diffuse faster in solution than $\mathrm{Mg}^{2+}$ as it needs smaller amount of water molecule to solvate. $\mathrm{Na}^{+}$ show highest diffusion due to weakest hydrogen bonding which will be evident in the subsequent sections. We simulated similar systems studied in the literature ${ }^{17-19}$ and compared ReaxFF selfdiffusion coefficients results and reported them in Table 6. The qualitative trend agrees very well and our present results are within $\sim 5 \%$ of those studies. The statistical uncertainty evaluated in the results are due to the system size effects and the shear viscosity obtained for each configuration at different temperatures.

Table 6: Comparisons of ReaxFF self-diffusion coefficient with literature

\begin{tabular}{ccccccccc} 
& $\mathrm{Ca}^{2+}$ & \multicolumn{3}{c}{$\mathrm{Mg}^{2+}$} & \multicolumn{3}{c}{$\mathrm{Na}^{+}$} & $\mathrm{CO}_{3}{ }^{2-}$ \\
\cline { 2 - 8 } & Present & $\begin{array}{c}\text { Raiteri } \\
\text { et al }{ }^{18}\end{array}$ & Present & $\begin{array}{c}\text { Raiteri } \\
\text { et al }{ }^{17}\end{array}$ & Present & $\begin{array}{c}\text { Ottochian } \\
\text { et al }{ }^{19}\end{array}$ & Present & $\begin{array}{c}\text { Raiteri } \\
\text { et al }^{17}\end{array}$ \\
\hline $\begin{array}{c}\mathrm{D}_{\mathrm{o}}\left(10^{-5}\right. \\
\left.\mathrm{cm}^{2} / \mathrm{s}\right)\end{array}$ & 0.89 & 0.95 & 0.79 & 0.86 & 0.91 & 1.2 & 1.03 & 0.8 \\
\hline
\end{tabular}

\subsection{Radial Distribution Function}

We computed the radial distribution function (RDF) of water and carbonate ions surrounding the metal ions to understand the interactions between each ion pairs. It is interesting to note the changes in intermolecular arrangements of atoms in aqueous metal carbonate solutions at ambient and supercritical temperature. The Me- $\mathrm{O}_{\mathrm{c}} \mathrm{RDFs}$ are shown in Figure 6a and 6d for $300 \mathrm{~K}$ and 700 $\mathrm{K}$ respectively. The probability of finding carbonate ions in the coordination shell of metal ions increases with increase in temperature. With the increase in size of cations, the position of RDF peaks of Me-O $\mathrm{O}_{\mathrm{c}}$ shifts towards larger ion-pair distances. Also, the shift in the position of the RDF 
peak can be attributed to the presence of carbonate or bicarbonate ion in the vicinity of the metal ions. Divalent ions predominantly form bicarbonates compared to monovalent ions due to lesser strain induced in the molecule in the form of $\mathrm{Me}^{-} \mathrm{O}_{\mathrm{c}}-\mathrm{C}$ angle. Me- $\mathrm{O}_{\mathrm{w}} \mathrm{RDFs}$ are shown in Figure $6 \mathrm{~b}$ and $6 \mathrm{e}$ for $300 \mathrm{~K}$ and $700 \mathrm{~K}$ respectively. We see a similar shift in the RDF peak owing to cation radius which is consistent with our previous studies at ambient ${ }^{22}$ and supercritical ${ }^{23}$ temperatures. However, divalent ions tend to form hydroxides predominantly compared to monovalent ions as it is more exothermic. The probability of finding water molecules in the coordination shell of the cations decreases with temperature. The carbonate solvation shells in each of the metal carbonate aqueous solutions were investigated from their interaction with water molecules as seen in RDF in Figure 6c and 6f. The radius of the solvation shell of carbonate ions increases with increase in temperature due to vapor formation at high temperature. The number of water molecules also increases surrounding the carbonate ions. Coordination shell of carbonate ions in aqueous $\mathrm{Na}_{2} \mathrm{CO}_{3}$ solution increases leading to lesser availability of water to interact with $\mathrm{Na}^{+}$ions as seen in Figure 6e. High temperature leads to protonation as seen from small first peak in Figure of for $\mathrm{Na}_{2} \mathrm{CO}_{3}$ aqueous solution.

The radius of the first coordination shell and the coordination numbers $(\mathrm{CN})$ are calculated and shown in Table 7 for all the RDFs illustrated in Figure 6. We use the radius of the coordination shell to calculate $\mathrm{CN}$ as given by Equation 6 .

$N_{i j}=\int_{0}^{R_{\min }} 4 \pi \rho_{j} r^{2} g_{i j}(r) d r$

where $N_{i j}$ represents the number of atoms of type $\mathrm{j}$ having a number density of $\rho_{j}$ surrounding the species $i$ in a shell extending from 0 to $R_{\min }$ in the RDF $g_{i j}(r)$. The $\mathrm{CN}$ of ion increases with the increase in cationic radius for water. On the other hand, the $\mathrm{CN}$ of the cations decreases as the 
water density decreases due to phase transition of water from liquid to vapor and the increased diffusivity of ions.
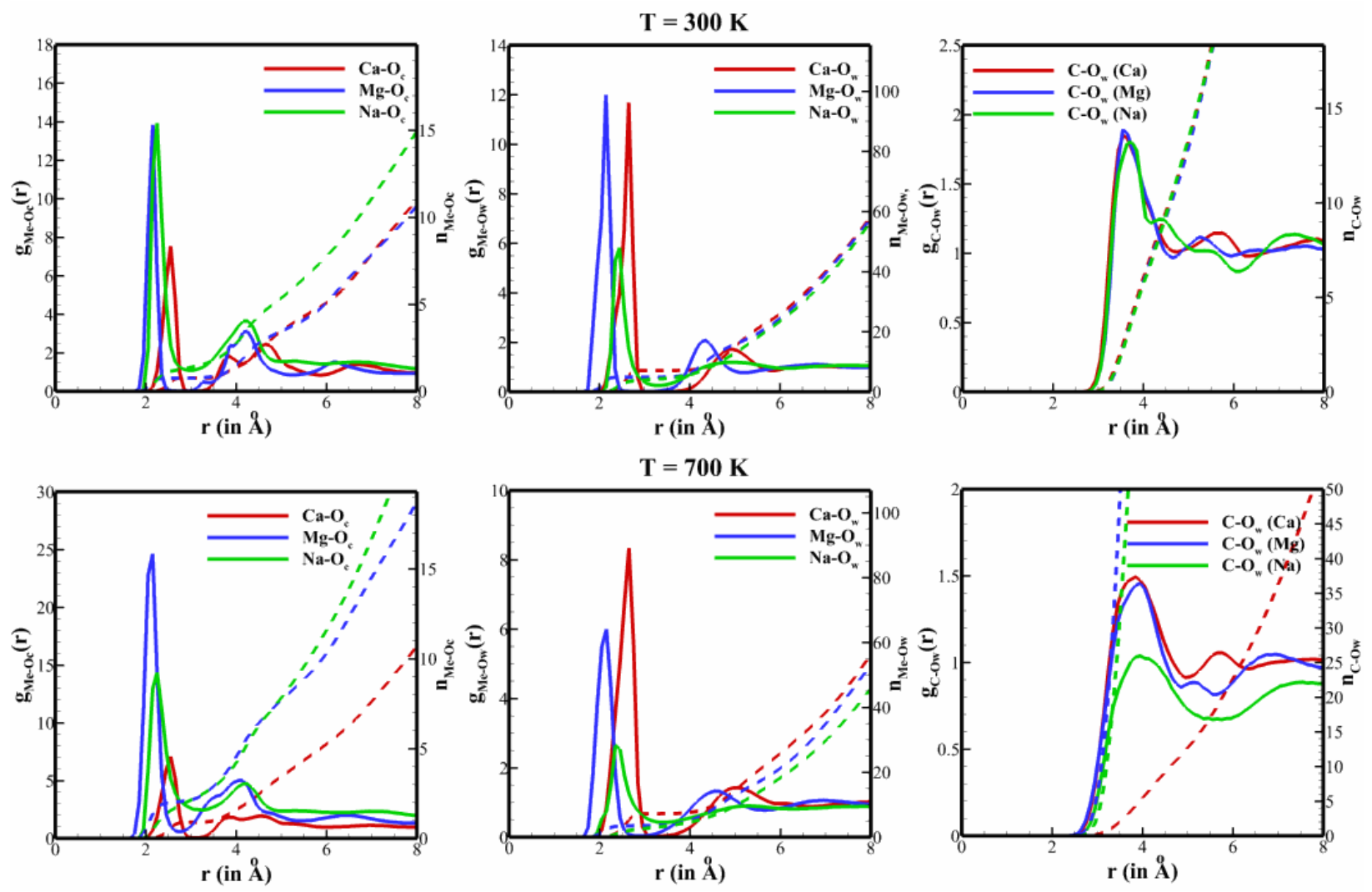

Figure 6: Radial distribution function of $\mathrm{Me}-\mathrm{O}_{\mathrm{c}}$ at (a) $300 \mathrm{~K}$ and (d) $700 \mathrm{~K}, \mathrm{Me}-\mathrm{O}_{\mathrm{w}}$ at (b) $300 \mathrm{~K}$ and (e) $700 \mathrm{~K}$ and $\mathrm{C}-\mathrm{O}_{\mathrm{w}}$ at (c) $300 \mathrm{~K}$ and (f) $700 \mathrm{~K}$. 
Table 7: Radius of first coordination shell and coordination numbers $(\mathrm{CN})$ of ion-pairs

\begin{tabular}{ccccc} 
& \multicolumn{2}{c}{$\mathrm{T}=300 \mathrm{~K}$} & \multicolumn{2}{c}{$\mathrm{T}=700 \mathrm{~K}$} \\
\cline { 2 - 5 } & $\mathrm{r}$ (in $\mathrm{A})$ & $\mathrm{CN}$ & $\mathrm{r}$ (in $\mathrm{A})$ & $\mathrm{CN}$ \\
\hline $\mathrm{Ca}^{2+}-\mathrm{O}_{\mathrm{c}}$ & 3.05 & 0.765 & 3.05 & 0.902 \\
$\mathrm{Mg}^{2+}-\mathrm{O}_{\mathrm{c}}$ & 2.75 & 0.751 & 2.75 & 2.051 \\
$\mathrm{Na}^{+}-\mathrm{O}_{\mathrm{c}}$ & 3.05 & 1.415 & 3.25 & 2.465 \\
$\mathrm{Ca}^{2+}-\mathrm{O}_{\mathrm{w}}$ & 3.25 & 7.116 & 3.25 & 7.237 \\
$\mathrm{Mg}^{2+}-\mathrm{O}_{\mathrm{w}}$ & 2.95 & 4.874 & 2.85 & 3.541 \\
$\mathrm{Na}^{+}-\mathrm{O}_{\mathrm{w}}$ & 3.35 & 4.332 & 3.45 & 3.425 \\
$\mathrm{C}-\mathrm{O}_{\mathrm{w}}\left(\mathrm{Ca}^{2+}\right)$ & 4.75 & 11.314 & 4.95 & 12.334 \\
$\mathrm{C}-\mathrm{O}_{\mathrm{w}}\left(\mathrm{Mg}^{2+}\right)$ & 4.65 & 10.245 & 4.85 & 10.992 \\
$\mathrm{C}-\mathrm{O}_{\mathrm{w}}\left(\mathrm{Na}^{+}\right)$ & 4.15 & 6.723 & 5.35 & 11.534 \\
\hline
\end{tabular}

$\mathrm{Me}-\mathrm{CO}_{3}{ }^{2-}$ pair $\mathrm{RDF}$ shows that the magnitude of the first peak increases with the decrease in size of ions. From the integral we deduce the presence of one $\mathrm{CO}_{3}{ }^{2-}$ ion on an average within the vicinity of cations. On an average, $\mathrm{Ca}^{2+}$ shows a 7-fold coordination, followed by $\mathrm{Mg}^{2+}$ and $\mathrm{Na}^{+}$ showing close to 6-fold coordination. Both $\mathrm{Ca}^{2+}$ and $\mathrm{Mg}^{2+}$ is likely to form a monodentate carbonate at ambient temperature as reported previously by Raiteri et al ${ }^{17}$ owing to the presence of 5 or more water molecules in the coordination shell. It is also more convenient to form bicarbonates with $\mathrm{Ca}^{2+}$ and $\mathrm{Mg}^{2+}$ compared to carbonates due to release of hydration energy on solvation. One of the ions present in the sodium coordination shell can be another $\mathrm{Na}^{+}$ion as it is likely to bind with a carbonate ion to form sodium carbonate. However, $\mathrm{Na}^{+}$and $\mathrm{Ca}^{2+}$ can have two or higher number of $\mathrm{CO}_{3}{ }^{2-}$ ion within their coordination shell at high temperature as they tend to nucleate. The $\mathrm{C}^{-} \mathrm{O}_{\mathrm{w}} \mathrm{RDF}$ displayed in Figure $6 \mathrm{c}$ and $6 \mathrm{f}$ for two different temperatures show an increase in radius of first coordination shell of the carbonate ion. This means lesser protonation occurring at high temperature. We compared the radius of the first coordination shell and the 
coordination number of the different metal carbonate systems and illustrated them in Table 8 . We find a reasonable comparison with the literature studies.

Table 8: Comparisons of coordination number $(\mathrm{CN})$ of the first solvation shell and radius of the first coordination shell of the metal and carbonate ions with literature.

\begin{tabular}{|c|c|c|c|c|c|c|c|c|}
\hline & \multirow{2}{*}{$\frac{\mathrm{Ca}^{2+}}{\text { Present }}$} & \multicolumn{3}{|c|}{$\mathrm{Mg}^{2+}$} & \multirow{2}{*}{$\frac{\mathrm{Na}^{+}}{\text {Present }}$} & \multicolumn{3}{|c|}{$\mathrm{CO}_{3}{ }^{2-}$} \\
\hline & & $\begin{array}{l}\text { Raiteri } \\
\text { et al }^{18}\end{array}$ & Present & $\begin{array}{l}\text { Raiteri } \\
{\text { et } \mathrm{l}^{17}}\end{array}$ & & $\begin{array}{l}\text { Ottochian } \\
\text { et al }^{19}\end{array}$ & Present & 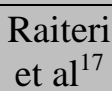 \\
\hline $\mathrm{CN}$ & 6.97 & 7.2 & 5.88 & 6 & 5.67 & 5.93 & 8.57 & 9.1 \\
\hline $\begin{array}{l}\mathrm{r}_{\text {Me-Ow }} \\
\text { (in } \AA \text { ) }\end{array}$ & 2.89 & 2.36 & 2.78 & 2 & 2.91 & 2.39 & 3.19 & 3.35 \\
\hline
\end{tabular}

\subsection{Angle Distribution Function}

The Angular distribution function (ADF) provides the orientational distribution of the atoms within the system. In order to understand the solvation dynamics of the electrolytes in water, it is important to figure the point of protonation or carbonation of the metal ions. The angular strain is an important parameter which guides the protonation and carbonation events. Too much strain during the events lead to unfeasible reaction and the event is non-exergonic. We have calculated the probability distribution of $\mathrm{Me}-\mathrm{O}_{\mathrm{w}}-\mathrm{H}$ and $\mathrm{Me}-\mathrm{O}_{\mathrm{c}}-\mathrm{C}$ angles based on the trajectories of the MD simulations. Figure 7 represent the angular distribution of $\mathrm{Me}-\mathrm{O}_{\mathrm{c}}-\mathrm{C}$ and $\mathrm{Me}-\mathrm{O}_{\mathrm{w}}-\mathrm{H}$ angles at 300 $\mathrm{K}$ and $700 \mathrm{~K}$. Ca and $\mathrm{Mg}$ peaks were found to be within similar range while Na peaks are at different range. The formation of $\mathrm{Na}-\mathrm{O}_{c}-\mathrm{C}$ is predominant compared to $\mathrm{Ca}-\mathrm{O}_{\mathrm{c}}-\mathrm{C}$ or $\mathrm{Mg}-\mathrm{O}_{\mathrm{c}}-\mathrm{C}$ due to lesser strain in their respective carbonate molecule. Also, $\mathrm{Na}_{2} \mathrm{CO}_{3}$ is formed when two molecules of $\mathrm{Na}$ react with $\mathrm{CO}_{3}{ }^{2-}$ leading to larger release in energy in the solution. On the other hand $\mathrm{Ca}(\mathrm{OH})_{2}$ formation is more likely compared to $\mathrm{Na}-\mathrm{O}_{\mathrm{w}}-\mathrm{H}$ as the angle of $\mathrm{Ca}-\mathrm{O}_{\mathrm{w}}-\mathrm{H}$ is wider and lesser strain is induced for the event to occur. The preferential angular orientation of $\mathrm{CaCO}_{3}$ is in between $120^{\circ}$ to $150^{\circ}$ and that of $\mathrm{MgCO}_{3}$ is mostly around $90^{\circ}$ followed by $120^{\circ}$. This can be 
attributed to the fact that $\mathrm{CaCO}_{3}$ prefers to be monodentate and exist as $\mathrm{Ca}\left(\mathrm{HCO}_{3}\right)_{2}$ and $\mathrm{MgCO}_{3}$ can exist as both monodentate and bidentate in solution. The possibility of forming $\mathrm{MgCO}_{3}$ is larger compared to $\mathrm{CaCO}_{3}$ as $\mathrm{Mg}^{+}$ions are smaller in size and bonding with carbonate ion will release more energy on formation of $\mathrm{MgCO}_{3} . \mathrm{Na}_{2} \mathrm{CO}_{3}$ exist in solution as carbonates as the $\mathrm{Na}-$ $\mathrm{O}_{\mathrm{c}-\mathrm{C}}$ angle is wider and releases more energy on solvation. At high temperature the preferential distribution of the angles broadens and the orientational preference of the ions in the coordination shell gets disrupted. The Me- $\mathrm{O}_{\mathrm{w}}-\mathrm{H}$ angle distribution as shown in Figure $7 \mathrm{a}$ and $7 \mathrm{~b}$ are found to be between $60^{\circ}$ and $90^{\circ}$ for $\mathrm{Ca}$ and $\mathrm{Mg}$ solutions primarily whereas for $\mathrm{Na}$, the peak distribution is found at $120^{\circ}$. The $\mathrm{Me}-\mathrm{O}_{\mathrm{w}}-\mathrm{H}$ angle distribution is different for monovalent and divalent ions as $\mathrm{Na}^{+}$binds with one water and $\mathrm{Ca}^{2+}, \mathrm{Mg}^{2+}$ tends to bind with two water. Solvation at $300 \mathrm{~K}$ show prominent peaks at certain angle which is a representation of n-fold coordination. At high temperature, ions lose their residual charge breaking the orientational preference of water. The spectrum of $\mathrm{Me}-\mathrm{O}_{\mathrm{w}}-\mathrm{H}$ angle distribution becomes broader at high temperature.
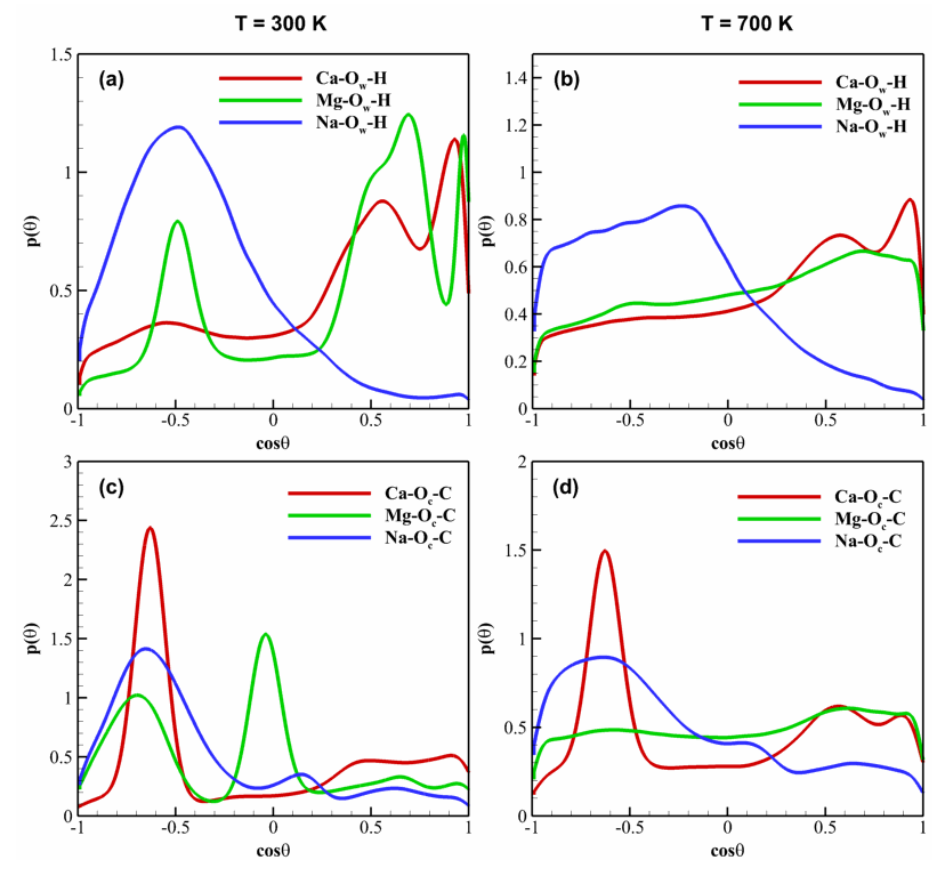

Figure 7: Angular distribution function of $\mathrm{Me}^{-} \mathrm{O}_{\mathrm{w}}-\mathrm{H}$ and $\mathrm{Me}-\mathrm{O}_{\mathrm{c}}-\mathrm{C}$ at $300 \mathrm{~K}$ (a) and (c) and at 700 $\mathrm{K}$ (b) and (d). 


\subsection{Solvation shell dynamics}

The dynamical nature of the carbonate ions in water can be explained based on the calculation of the residence time distribution. It reveals the retarded mobility of the hydration shell water molecules and carbonate ions. It is directly related to the diffusion coefficient, charge and size of ions. The residence time distribution of the carbonate ion and water molecules in the coordination shell of metal ions was calculated to understand the strength of the $\mathrm{Me}_{-} \mathrm{O}_{\mathrm{c}}$ and $\mathrm{Me}-\mathrm{O}_{\mathrm{w}}$ bonds. We estimate the residence time of a water molecule and carbonate ion in the first coordination shell of the metal ion from the following Eq. 7 and Eq. 8 respectively.

$C_{w}(t)=\frac{1}{N_{O_{w}}} \sum_{o_{w}}\left\langle h_{M e O_{w}}(0) h_{M e O_{w}}(t)\right\rangle$

$C_{C}(t)=\frac{1}{N_{O_{c}}} \sum_{O_{c}}\left\langle h_{\mathrm{MeO}_{c}}(0) h_{\mathrm{MeO}_{c}}(t)\right\rangle$

Where $h$ is the characteristic function and $N$ is the no of carbonate ions and water molecules present in the first coordination shell. Figure 8 represents the residence time distribution of different metal carbonate systems at $300 \mathrm{~K}$ and $700 \mathrm{~K}$. 

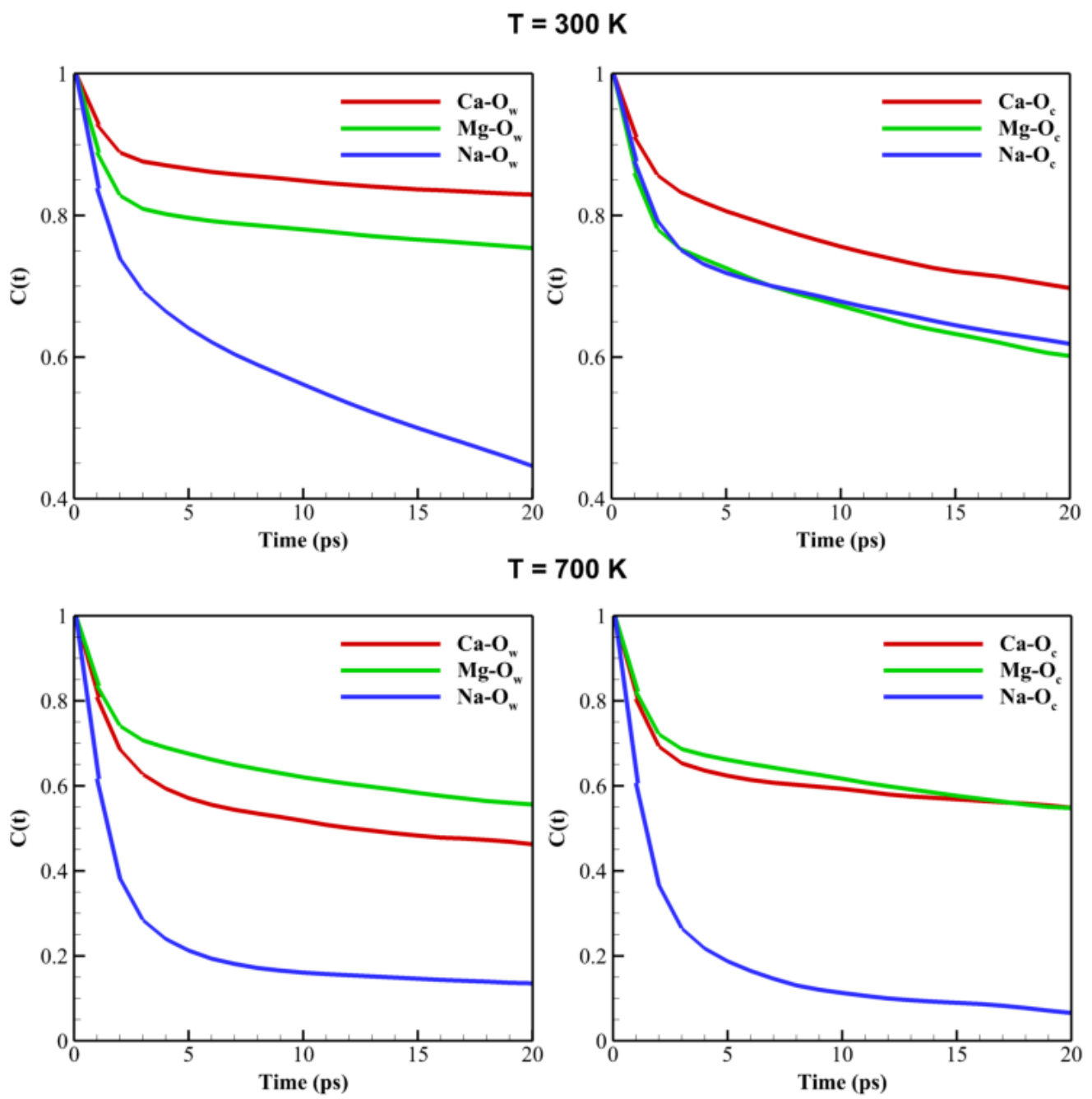

Figure 8: Residence time distribution of water molecules and carbonate ions systems at $300 \mathrm{~K}$ and $700 \mathrm{~K}$.

Calcium and Magnesium shows strong water retaining capability compared to Sodium. This is because $\mathrm{Ca}^{2+}$ and $\mathrm{Mg}^{2+}$ are bivalent cations and can bind with two water molecules leading which leads to release of more hydration energy. The formation of $\mathrm{Ca}-\mathrm{O}_{\mathrm{w}}-\mathrm{H}$ angle induces lesser strain compared to $\mathrm{Na}-\mathrm{O}_{\mathrm{w}}-\mathrm{H}$ angle making the binding favorable. At high temperature, the residence time decreases for both water molecules and carbonate ions as the metal ions lose their dielectric strength. Sodium shows stronger attraction towards carbonate ions at ambient temperature due to less strained $\mathrm{Na}-\mathrm{O}_{\mathrm{c}}-\mathrm{C}$ angle compared to $\mathrm{Ca}-\mathrm{O}_{\mathrm{c}}-\mathrm{C}$ angle or $\mathrm{Mg}-\mathrm{O}_{\mathrm{c}}-\mathrm{C}$ angle. This leads to slower 
exchange of carbonate ions in the coordination shell of $\mathrm{Na}^{+}$compared to $\mathrm{Ca}^{2+}$ and $\mathrm{Mg}^{2+}$ shells. At high temperature, the mobility of ions back and forth inside coordination shell is very random and as such the dynamics is difficult to establish between the alkaline and alkaline earth metal ions. This phenomenon can be attributed to the nucleation of metal ions with carbonate ions forming clusters which eventually settles in the solution. At ambient temperature, the lifetime of carbonate ion is larger than that of water molecule which is in accord with the result of an earlier ab-initio MD study. ${ }^{7}$ Carbonate ions being more basic than water binds strongly with metal ions.

\subsection{Protonation of carbonate ions}

The EEM charge equilibration scheme which is applied to calculate partial atomic charges for the Coulomb interaction along with the covalent terms in the ReaxFF framework can effectively capture the ionization of carbonate ions in solution. The protonation of carbonate ions in solution is an indicator of the degree of solvation by metal ions. We calculate the formation of hydrogen bonds in the form of bicarbonate ions during the course of MD simulation. We calculated the protonation of carbonate ions in each system from the following criteria: $\mathrm{O}-\mathrm{H}$ bond lengths for $\mathrm{CaCO}_{3}, \mathrm{MgCO}_{3}$ and $\mathrm{Na}_{2} \mathrm{CO}_{3}$ within $1.2 \mathrm{~A}$ and $\angle \mathrm{COH}$ within $80^{\circ}$ to $120^{\circ}$ for $\mathrm{CaCO}_{3}, \mathrm{MgCO}_{3}$ and $\mathrm{Na}_{2} \mathrm{CO}_{3}$ solutions at $300 \mathrm{~K}$ and $700 \mathrm{~K}$. Figure 9 represent the evolution of ionization of carbonate ions due to the presence of metal ions. The vibrational frequencies of the water molecule in the vicinity of metal and carbonate ions get significantly altered. Yadav and Chandra ${ }^{46}$ reported that the vibrational frequency of $\mathrm{OH}$ modes of hydrogen bonded to the ions is found to be smaller than that of bulk water, which means the carbonate ion-water hydrogen bonds are stronger than those between water molecules. The $\mathrm{O}_{\mathrm{c}}-\mathrm{H}$ average bond distance in the system is also found to be lesser than the water-water hydrogen bonds. The bicarbonate ion formation increases for all the systems over the course of the simulation and the carbonate ions deplete as seen in Figure 9. We find that 
$\mathrm{Ca}^{2+}$ and $\mathrm{Mg}^{2+}$ show a similar behavior at $300 \mathrm{~K}$ where there is rapid ionization during the initial time period $(0 \mathrm{ps}-200 \mathrm{ps})$ and then a stabilization as the water molecules establishes their hydrogen bonding network in the system. It is intuitive to say that calcium and magnesium form bicarbonates at ambient conditions. Based on our previous structural analysis, we found that sodium prefers the formation of carbonates over bicarbonates. Although we do see a steady decline of carbonate ions in the aqueous sodium carbonate solution, the number of carbonate ions are overwhelming to bind with sodium. $\mathrm{Ca}^{2+}$ and $\mathrm{Mg}^{2+}$ forms stable hydroxides or binds with two water molecules which initiates the non-reacting proton to interact with carbonate ions leading to formation of more bicarbonates. At high temperature we find that the fluctuations in the bicarbonate and carbonate ions almost remain stable. High temperature leads to breakdown dielectric strength leading to high diffusivity of ions and water molecules in turn forming disorganized and sporadic hydrogen bonding networks in the solution. Protonation significantly decreases at high temperature. As protonation decreases at high temperature, the residual charge on metal ions left attracts the carbonate ions within the solution. This is the advent of metal carbonate nucleating clusters which is driven by thermodynamics.
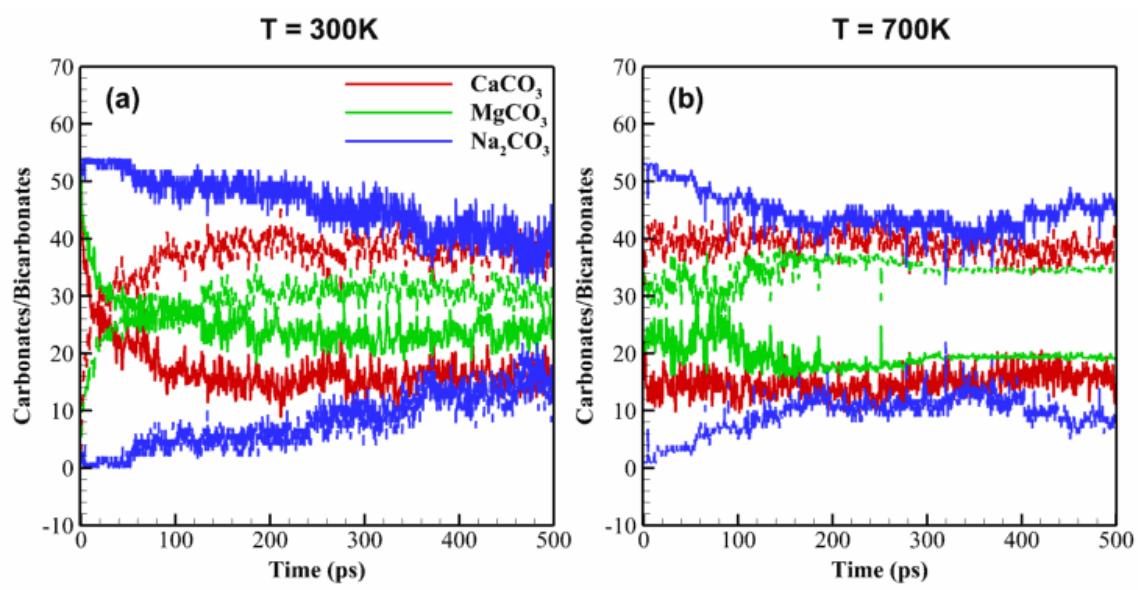

Figure 9: Speciation of carbonates (solid) and bicarbonates (dashed) ions in the solutions at (a) $300 \mathrm{~K}$ and (b) $700 \mathrm{~K}$ 


\subsection{Nucleation of carbonate salts}

Classical theory of thermodynamics can describe nucleation of ions within the solution at supercritical temperature. Nucleation is the beginning of phase transition which is characterized by a sudden jump in temperature. Composition fluctuations within a metastable phase lead to nucleation of ions. A new phase emerges at the expense of an interfacial energy which gradually decreases with the decrease in surface to volume ratio of clusters. Due to dielectric breakdown of ions and water molecules, the hydrogen bonding considerably weakens leading to the agglomeration of carbonate and metal ions in the solution. We calculated the average number of clusters forming over time for the three different salt systems at $300 \mathrm{~K}$ and $700 \mathrm{~K}$ and reported in Figure 10a, 10b and 10c. Clearly, the salt clusters increase over time for all three different metal carbonate systems at high temperature. The nucleation of carbonates increases steadily over time for $\mathrm{MgCO}_{3}$ and $\mathrm{Na}_{2} \mathrm{CO}_{3}$ at $700 \mathrm{~K}$ leading to large clusters within the system and limiting the diffusion of metal and carbonate ions. Prenucleation at $300 \mathrm{~K}$ is rare for these systems owing to the well-formed hydrogen bond networks and solvation of metal ions. Saturated solutions might form prenucleation clusters at ambient condition due to strong metal non-metal attraction which might overlap the coordination shells. The mechanism of calcium carbonate precipitation allows for early structural preformation during the pre-nucleation stage which occurs at a particular temperature between $300 \mathrm{~K}$ and $700 \mathrm{~K}$ leading to post-nucleation and settling at $700 \mathrm{~K}$. In the classical view, in contrast, early structural preformation is not facilitated because ionic solutions form clusters randomly. Generally, the nucleation originates at a particular thermodynamic condition and the critical stage is characterized by the stochastic formation of clusters of critical sizes, which are thermodynamically able to grow without limit but are in fact a rare species. The growth of these clusters is then considered to take place by the addition of single ions, and the 
formation of different polymorphs is considered to be under thermodynamic or kinetic control. We also calculated the number of clusters containing more than five ions for the three different carbonate systems and reported them in Figure 10d, 10e and 10f. We consider clusters containing greater than five metal and carbonate ions are big and check their evolution over time. We find that such clusters grow steadily over time at high temperature and stagnates after post $1.5 \mathrm{ps}$. Unlike $\mathrm{Na}^{+}, \mathrm{Ca}^{2+}$ and $\mathrm{Mg}^{2+}$ show a classic growth in cluster which is accentuated with temperature. A representation of big cluster as shown in Figure 11 is found in our MD trajectory containing multiple $\mathrm{Mg}^{2+}$ ions binding with $\mathrm{CO}_{3}{ }^{2-}$ ions to form a chelate in the solution. Our discussion on nucleation of carbonates in the solution can be extended to the fact that formation of carbonate minerals is a means for long-term carbon dioxide sequestration while is being utilized in a number of industrial processes. Given this range of contexts in which carbonates are significant, there has been considerable interest in its crystallization pathways, something that has been further heightened by the debate regarding so-called "nonclassical" nucleation mechanisms. ${ }^{47}$ There is already a growing body of evidence that formation of carbonates is a complex process that can involve multiple steps, which may include formation of prenucleation clusters, liquid-liquid phase separation, precipitation of polymorphs of amorphous carbonates, and transient crystallization to disordered crystals, depending on the thermodynamic condition and finally transforming into the most stable phase at ambient condition. 

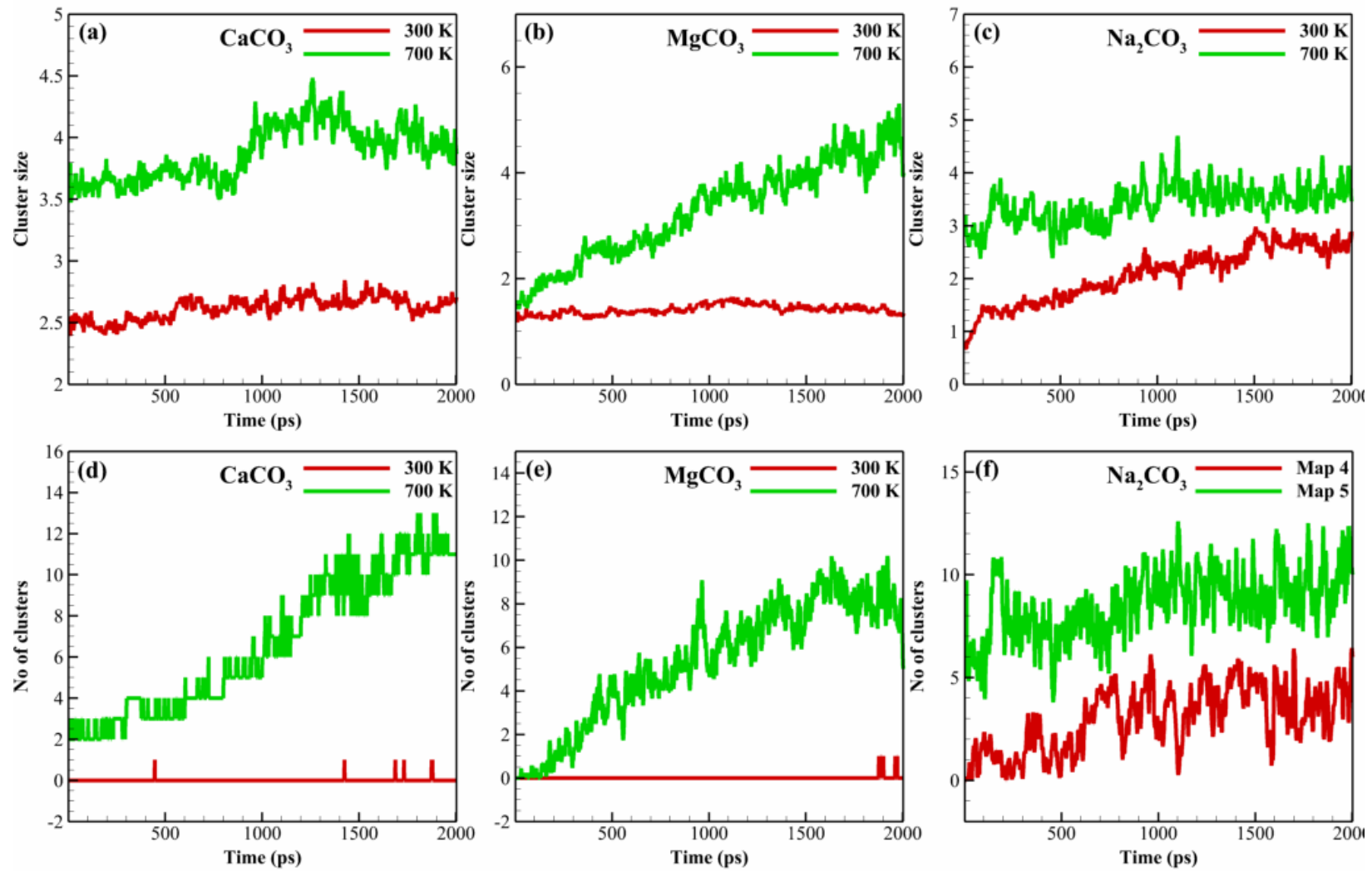

Figure 10: Average cluster size distribution over the period of time for (a) $\mathrm{CaCO}_{3}$ (b) $\mathrm{MgCO}_{3}$ and (c) $\mathrm{Na}_{2} \mathrm{CO}_{3}$ at $300 \mathrm{~K}$ and $700 \mathrm{~K}$; No of clusters formed greater than size five for (a) $\mathrm{CaCO}_{3}$ (b) $\mathrm{MgCO}_{3}$ and (c) $\mathrm{Na}_{2} \mathrm{CO}_{3}$ at $300 \mathrm{~K}$ and $700 \mathrm{~K}$.

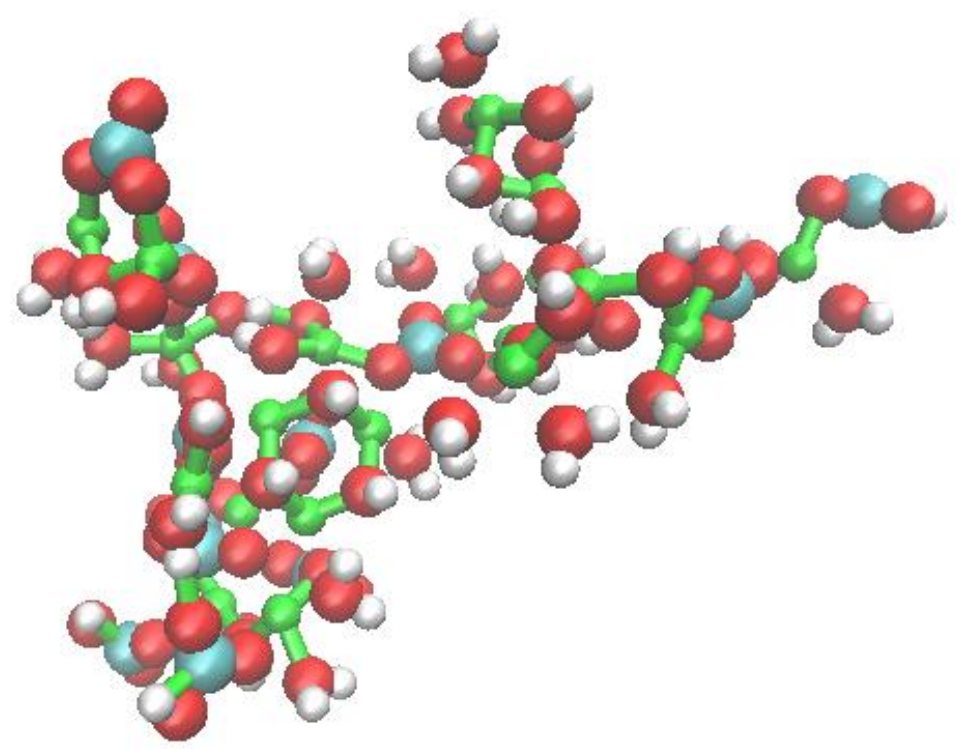

Figure 11: $\mathrm{An} \mathrm{MgCO}_{3}$ cluster found at $700 \mathrm{~K}$ containing $20 \mathrm{Mg}^{2+}$ ions and $11 \mathrm{CO}_{3}^{2-}$ ions $\left(\mathrm{Mg}^{2+}\right.$ (green), C (cyan), O (red), $\mathrm{H}$ (white)). 


\section{Conclusions}

A new ReaxFF force field has been developed for the metal carbonate system including alkali metal ion $\left(\mathrm{Na}^{+}\right)$, alkaline-earth metal ion $\left(\mathrm{Ca}^{2+}, \mathrm{Mg}^{2+}\right)$ and carbonate ion $\left(\mathrm{CO}_{3}^{2-}\right)$. Unlike, the previous parameterization by Gale et al. ${ }^{27}$, the charge on the metal ions are kept dynamic by calculating the partial charges on the atoms updated in every iterations based on their surroundings, making this ReaxFF description directly transferable with ReaxFF for other materials and molecules. We optimized the three-body valence angle $\mathrm{Me}-\mathrm{O}_{\mathrm{c}}-\mathrm{C}$ parameters and non-reactive parameters defining the Me-C interactions against ab-initio data based on mechanical strain, heat of formation, heat of reaction, angle scanning and molecular vibrational frequencies. The force field predictions are found to be within $10 \%$ of the DFT calculations.

We performed ReaxFF MD simulations for aqueous metal carbonate solutions at $300 \mathrm{~K}$ and 700 $\mathrm{K}$. The structural behavior of each system is understood on the basis of radial distribution function (RDF) and Angular distribution function (ADF). From the RDF we were able to reproduce the radius of the coordination shell for the metal and carbonate ions which were in very close agreement with the non-reactive and ab-initio studies done in the literature. From the ADF we were been able to deduce the stability of carbonates and bicarbonates in each system based on the orientational preferences of carbonate ions in the coordination shell.

The MSD analysis elucidated the diffusion of the various ions in the system. We found that diffusion is proportional to the size and charge density of ions in the solution. With temperature, mobility of ions in the solution increases due to the disruption in the hydrogen bonding network. The dynamical behavior of each system was established from the residence time distribution correlations which explains the delay and exchange of carbonate ions and water molecules in the coordination shell. We used our new ReaxFF force field to compute the ionization capability of 
carbonate ions in water. The reactivity of the system was addressed by calculating the formation and depletion of bicarbonate and carbonate ions respectively. The ionization calculations support the claim that sodium binds with carbonates strongly compared to calcium and magnesium which aligns with our structural analysis. Finally, in order to find a relation between ion nucleation and thermodynamics we computed the evolution of metal carbonate clusters in the solution in the form of average cluster size and number of big clusters. Although the two sets of results are in qualitative agreement, there are quantitative differences computed here. We find that the formation of $\mathrm{MgCO} 3$

clusters is substantially less exothermic at ambient condition compared to sodium and calcium but it is greatly accelerated with temperature.

\section{References}

(1) Busch, A.; Alles, S.; Gensterblum, Y.; Prinz, D.; Dewhurst, D. N.; Raven, M. D.; Stanjek, H.; Krooss, B. M. Carbon Dioxide Storage Potential of Shales. Int. J. Greenh. Gas Control 2008, 2 (3), 297-308. https://doi.org/https://doi.org/10.1016/j.ijggc.2008.03.003.

(2) Patra, S. G.; Mizrahi, A.; Meyerstein, D. The Role of Carbonate in Catalytic Oxidations. Acc. Chem. Res. 2020, 53 (10), 2189-2200. https://doi.org/10.1021/acs.accounts.0c00344.

(3) Dosmukhamedov, N.; Kaplan, V. Flue Gas Purification from SO2 and NOx Using Molten Mixture of Alkali Metal Carbonates. Int. J. Coal Prep. Util. 2021, 1-12. https://doi.org/10.1080/19392699.2021.1931147.

(4) Desmaele, E.; Sator, N.; Vuilleumier, R.; Guillot, B. The MgCO3-CaCO3-Li2CO3Na2CO3-K2CO3 Melts: Thermodynamics and Transport Properties by Atomistic Simulations. J. Chem. Phys. 2019, 150 (21), 214503. https://doi.org/10.1063/1.5099015.

(5) Tang, W.; Zhan, B.; Wu, C.; Kou, S. Experimental Investigation and Mathematical 
Modelling of the Carbon Dioxide Sequestration of Cement Pastes during Pressurized CO2 Curing. Constr. Build. Mater. 2021, 302, 124383.

https://doi.org/https://doi.org/10.1016/j.conbuildmat.2021.124383.

(6) Raiteri, P.; Gale, J. D. Water Is the Key to Nonclassical Nucleation of Amorphous Calcium Carbonate. J. Am. Chem. Soc. 2010, 132 (49), 17623-17634. https://doi.org/10.1021/ja108508k.

(7) Bruneval, F.; Donadio, D.; Parrinello, M. Molecular Dynamics Study of the Solvation of Calcium Carbonate in Water. J. Phys. Chem. B 2007, 111 (42), 12219-12227. https://doi.org/10.1021/jp0728306.

(8) Kumar, P. P.; Kalinichev, A. G.; Kirkpatrick, R. J. Hydrogen-Bonding Structure and Dynamics of Aqueous Carbonate Species from Car-Parrinello Molecular Dynamics Simulations. J. Phys. Chem. B 2009, 113 (3), 794-802. https://doi.org/10.1021/jp809069g.

(9) Elhadj, S.; De Yoreo, J. J.; Hoyer, J. R.; Dove, P. M. Role of Molecular Charge and Hydrophilicity in Regulating the Kinetics of Crystal Growth. Proc. Natl. Acad. Sci. U. S. A. 2006, 103 (51), 19237-19242.

(10) Pokrovsky, O. S.; Schott, J. Surface Chemistry and Dissolution Kinetics of Divalent Metal Carbonates. Environ. Sci. Technol. 2002, 36 (3), 426-432. https://doi.org/10.1021/es010925u.

(11) Gebauer, D.; Völkel, A.; Cölfen, H. Stable Prenucleation Calcium Carbonate Clusters. Science (80-. ). 2008, 322 (5909), 1819 LP - 1822. https://doi.org/10.1126/science.1164271. 
(12) Tommaso, D. Di; de Leeuw, N. H. The Onset of Calcium Carbonate Nucleation: A Density Functional Theory Molecular Dynamics and Hybrid Microsolvation/Continuum Study. J. Phys. Chem. B 2008, 112 (23), 6965-6975. https://doi.org/10.1021/jp801070b.

(13) Di Tommaso, D.; Ruiz-Agudo, E.; de Leeuw, N. H.; Putnis, A.; Putnis, C. V. Modelling the Effects of Salt Solutions on the Hydration of Calcium Ions. Phys. Chem. Chem. Phys. 2014, 16 (17), 7772-7785. https://doi.org/10.1039/C3CP54923B.

(14) Tommaso, D. Di; de Leeuw, N. H. Structure and Dynamics of the Hydrated Magnesium Ion and of the Solvated Magnesium Carbonates: Insights from First Principles Simulations. Phys. Chem. Chem. Phys. 2010, 12 (4), 894-901. https://doi.org/10.1039/B915329B.

(15) Chaka, A. M. Ab Initio Thermodynamics of Hydrated Calcium Carbonates and Calcium Analogues of Magnesium Carbonates: Implications for Carbonate Crystallization Pathways. ACS Earth Sp. Chem. 2018, 2 (3), 210-224. https://doi.org/10.1021/acsearthspacechem.7b00101.

(16) Tribello, G. A.; Bruneval, F.; Liew, C.; Parrinello, M. A Molecular Dynamics Study of the Early Stages of Calcium Carbonate Growth. J. Phys. Chem. B 2009, 113 (34), 1168011687. https://doi.org/10.1021/jp902606x.

(17) Raiteri, P.; Demichelis, R.; Gale, J. D. Thermodynamically Consistent Force Field for Molecular Dynamics Simulations of Alkaline-Earth Carbonates and Their Aqueous Speciation. J. Phys. Chem. C 2015, 119 (43), 24447-24458. https://doi.org/10.1021/acs.jpcc.5b07532.

(18) Raiteri, P.; Schuitemaker, A.; Gale, J. D. Ion Pairing and Multiple Ion Binding in Calcium 
Carbonate Solutions Based on a Polarizable AMOEBA Force Field and Ab Initio

Molecular Dynamics. J. Phys. Chem. B 2020, 124 (17), 3568-3582.

https://doi.org/10.1021/acs.jpcb.0c01582.

Ottochian, A.; Ricca, C.; Labat, F.; Adamo, C. Molecular Dynamics Simulations of a Lithium/Sodium Carbonate Mixture. J. Mol. Model. 2016, 22 (3), 61. https://doi.org/10.1007/s00894-016-2921-4.

(20) Van Duin, A. C. T.; Dasgupta, S.; Lorant, F.; Goddard, W. A. ReaxFF: A Reactive Force Field for Hydrocarbons. J. Phys. Chem. A 2001, 105 (41), 9396-9409.

(21) Senftle, T. P.; Hong, S.; Islam, M. M.; Kylasa, S. B.; Zheng, Y.; Shin, Y. K.; Junkermeier, C.; Engel-Herbert, R.; Janik, M. J.; Aktulga, H. M.; Verstraelen, T.; Grama, A.; van Duin, A. C. T. The ReaxFF Reactive Force-Field: Development, Applications and Future Directions. Npj Comput. Mater. 2016, 2, 15011.

(22) Dasgupta, N.; Kyung Shin, Y.; Fedkin, M. V; van Duin, A. C. T. ReaxFF Molecular Dynamics Simulations on the Structure and Dynamics of Electrolyte Water Systems at Ambient Temperature. Comput. Mater. Sci. 2020, 172, 109349. https://doi.org/https://doi.org/10.1016/j.commatsci.2019.109349.

(23) Dasgupta, N.; Shin, Y. K.; Fedkin, M. V; van Duin, A. ReaxFF Molecular Dynamics Simulations of Electrolyte-Water Systems at Supercritical Temperature. J. Chem. Phys. 2020, 152 (20), 204502. https://doi.org/10.1063/5.0006676.

(24) Shin, Y. K.; Sengul, M. Y.; Jonayat, A. S. M.; Lee, W.; Gomez, E. D.; Randall, C. A.; Duin, A. C. T. van. Development of a ReaxFF Reactive Force Field for Lithium Ion Conducting Solid Electrolyte Li1+xAlxTi2-x(PO4)3 (LATP). Phys. Chem. Chem. Phys. 
2018, 20 (34), 22134-22147. https://doi.org/10.1039/C8CP03586E.

(25) Hahn, S. H.; van Duin, A. C. T. Surface Reactivity and Leaching of a Sodium Silicate Glass Under Aqueous Environment: A ReaxFF Molecular Dynamics Study. J. Phys. Chem. C 2019.

(26) Muraleedharan, M. G.; Herz-Thyhsen, R.; Dewey, J. C.; Kaszuba, J.; van Duin, A. C. T. Understanding the Chemistry of Cation Leaching in Illite/Water Interfacial System Using Reactive Molecular Dynamics Simulations and Hydrothermal Experiments. Acta Mater. 2020, $186,564-574$.

(27) Gale, J. D.; Raiteri, P.; van Duin, A. C. T. A Reactive Force Field for Aqueous-Calcium Carbonate Systems. Phys. Chem. Chem. Phys. 2011, 13 (37), 16666-16679. https://doi.org/10.1039/C1CP21034C.

(28) Vařeková, R. S.; Jiroušková, Z.; Vaněk, J.; Suchomel, Š.; Koča, J. Electronegativity Equalization Method: Parameterization and Validation for Large Sets of Organic, Organohalogene and Organometal Molecule. Int. J. Mol. Sci. 2007, 8 (7), 572-582.

(29) Monti, S.; Corozzi, A.; Fristrup, P.; Joshi, K. L.; Shin, Y. K.; Oelschlaeger, P.; van Duin, A. C. T.; Barone, V. Exploring the Conformational and Reactive Dynamics of Biomolecules in Solution Using an Extended Version of the Glycine Reactive Force Field. Phys. Chem. Chem. Phys. 2013, 15 (36), 15062-15077. https://doi.org/10.1039/C3CP51931G.

(30) Chenoweth, K.; van Duin, A. C. T.; Goddard, W. A. ReaxFF Reactive Force Field for Molecular Dynamics Simulations of Hydrocarbon Oxidation. J. Phys. Chem. A 2008, 112 (5), 1040-1053. https://doi.org/10.1021/jp709896w. 
(31) van Duin, A. C. T.; Zou, C.; Joshi, K.; Bryantsev, V.; Goddard, W. A. CHAPTER 6 A Reaxff Reactive Force-Field for Proton Transfer Reactions in Bulk Water and Its Applications to Heterogeneous Catalysis. In Computational Catalysis; The Royal Society of Chemistry, 2014; pp 223-243. https://doi.org/10.1039/9781849734905-00223.

(32) Pitman, M. C.; Van Duin, A. C. T. Dynamics of Confined Reactive Water in Smectite Clay-Zeolite Composites. J. Am. Chem. Soc. 2012, 134 (6), 3042-3053.

(33) Fedkin, M. V.; Shin, Y. K.; Dasgupta, N.; Yeon, J.; Zhang, W.; Van Duin, D.; Van Duin, A. C. T.; Mori, K.; Fujiwara, A.; Machida, M.; Nakamura, H.; Okumura, M. Development of the ReaxFF Methodology for Electrolyte-Water Systems. J. Phys. Chem. A 2019, 123 (10). https://doi.org/10.1021/acs.jpca.8b10453.

(34) Muraleedharan, M. G.; Asgar, H.; Hahn, S. H.; Dasgupta, N.; Gadikota, G.; van Duin, A. C. T. Interfacial Reactivity and Speciation Emerging from Na-Montmorillonite Interactions with Water and Formic Acid at $200{ }^{\circ} \mathrm{C}$ : Insights from Reactive Molecular Dynamics Simulations, Infrared Spectroscopy, and X-Ray Scattering Measurements. ACS Earth Sp. Chem. 2021, 5 (5), 1006-1019. https://doi.org/10.1021/acsearthspacechem.0c00286.

Bhamra, J. S.; Ewen, J. P.; Latorre, C. A.; Bomidi, J. A. R.; Bird, M. W.; Dasgupta, N.; van Duin, A. C. T.; Dini, D. Interfacial Bonding Controls Friction in Diamond-Rock Contacts. J. Phys. Chem. C 2021. https://doi.org/10.1021/acs.jpcc.1c02857.

(36) Linstrom, P. J.; Mallard, W. G. The NIST Chemistry WebBook: A Chemical Data Resource on the Internet. J. Chem. Eng. Data 2001, 46 (5), 1059-1063.

(37) Bochevarov, A. D.; Harder, E.; Hughes, T. F.; Greenwood, J. R.; Braden, D. A.; Philipp, 
D. M.; Rinaldo, D.; Halls, M. D.; Zhang, J.; Friesner, R. A. Jaguar: A High-Performance Quantum Chemistry Software Program with Strengths in Life and Materials Sciences. Int. J. Quantum Chem. 2013, 113 (18), 2110-2142.

https://doi.org/https://doi.org/10.1002/qua.24481.

(38) Kresse, G.; Furthmüller, J. Efficient Iterative Schemes for Ab Initio Total-Energy

Calculations Using a Plane-Wave Basis Set. Phys. Rev. B 1996, 54 (16), 11169-11186. https://doi.org/10.1103/PhysRevB.54.11169.

(39) Blöchl, P. E. Projector Augmented-Wave Method. Phys. Rev. B 1994, 50 (24), 1795317979. https://doi.org/10.1103/PhysRevB.50.17953.

(40) Perdew, J. P.; Burke, K.; Ernzerhof, M. Generalized Gradient Approximation Made Simple. Phys. Rev. Lett. 1996, 77 (18), 3865-3868. https://doi.org/10.1103/PhysRevLett.77.3865.

(41) te Velde, G.; Bickelhaupt, F. M.; Baerends, E. J.; Fonseca Guerra, C.; van Gisbergen, S. J. A.; Snijders, J. G.; Ziegler, T. Chemistry with ADF. J. Comput. Chem. 2001, 22 (9), 931967. https://doi.org/10.1002/jcc.1056.

(42) de Leeuw, N. H.; Parker, S. C. Surface Structure and Morphology of Calcium Carbonate Polymorphs Calcite, Aragonite, and Vaterite: An Atomistic Approach. J. Phys. Chem. B 1998, 102 (16), 2914-2922. https://doi.org/10.1021/jp973210f.

(43) Raiteri, P.; Gale, J. D.; Quigley, D.; Rodger, P. M. Derivation of an Accurate Force-Field for Simulating the Growth of Calcium Carbonate from Aqueous Solution: A New Model for the Calcite-Water Interface. J. Phys. Chem. C 2010, 114 (13), 5997-6010. https://doi.org/10.1021/jp910977a. 
(44) Xiao, S.; Edwards, S. A.; Gräter, F. A New Transferable Forcefield for Simulating the Mechanics of CaCO3 Crystals. J. Phys. Chem. C 2011, 115 (41), 20067-20075. https://doi.org/10.1021/jp202743v.

(45) Yeh, I.-C.; Hummer, G. System-Size Dependence of Diffusion Coefficients and Viscosities from Molecular Dynamics Simulations with Periodic Boundary Conditions. $J$. Phys. Chem. B 2004, 108 (40), 15873-15879. https://doi.org/10.1021/jp0477147.

(46) Yadav, S.; Chandra, A. Structural and Dynamical Nature of Hydration Shells of the Carbonate Ion in Water: An Ab Initio Molecular Dynamics Study. J. Phys. Chem. B 2018, 122 (4), 1495-1504. https://doi.org/10.1021/acs.jpcb.7b11636.

(47) Gebauer, D.; Cölfen, H. Prenucleation Clusters and Non-Classical Nucleation. Nano Today 2011, 6 (6), 564-584. https://doi.org/https://doi.org/10.1016/j.nantod.2011.10.005. 